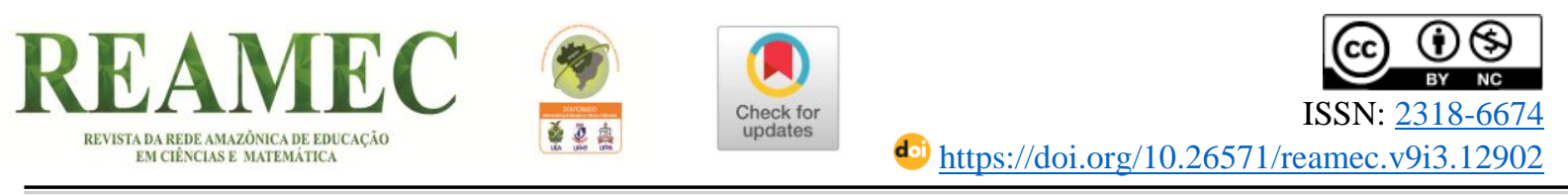

\title{
PRODUÇÃO CIENTÍFICA SOBRE OBJETOS DIGITAIS DE APRENDIZAGEM VOLTADOS PARA O ENSINO DE CIÊNCIAS (2016-2020)
}

\author{
SCIENTIFIC PRODUCTION ON DIGITAL LEARNING OBJECTS AIMED AT \\ SCIENCE TEACHING (2016-2020)
}

\section{PRODUCCIÓN CIENTÍFICA SOBRE OBJETOS DIGITALES DE APRENDIZAJE DIRIGIDOS A LA ENSEÑANZA DE LAS CIENCIAS (2016-2020)}

\author{
Jefferson Batistella $^{1}$ (iD) $\mathbb{0}$ \\ Marcelo Franco Leão ${ }^{2}$ (1) $\bullet$
}

\begin{abstract}
RESUMO
Objetos Digitais de Aprendizagem (ODA) têm contribuído para minimizar déficits de aprendizagem e para diminuir, de modo virtual, a distância entre estudantes e professores neste período de pandemia gerada pelo Coronavírus. O estudo teve como objetivo realizar o levantamento da produção científica nos últimos cinco anos (2016-2020) sobre os Objetos Digitais de Aprendizagem que estão sendo empregados no Ensino de Ciências. No que tange aos procedimentos metodológicos, essa pesquisa básica, descritiva e exploratória, de abordagem qualitativa, configura-se como estado do conhecimento. Esse levantamento bibliográfico considerou como recorte temporal os últimos 5 anos (2016-2020), e como base de dados os repositórios Periódicos CAPES e o SciELO. Das 398 publicações levantadas, selecionou-se 23 que tinham relação direta com o tema. Observou-se que o uso de ODA é mais recorrente no Ensino de Matemática, já no Ensino de Ciências sua utilização está voltada às atividades práticas. Notou-se que a investigação a campo e análise documental foram os tipos de pesquisa mais recorrentes e a abordagem qualitativa predominou. Os públicos mais investigados foram professores e estudantes e os ODA mais utilizados foram: vídeos, jogos digitais, plataformas de ensino, softwares, ferramentas do google e simuladores para o ensino. Quanto às tecnologias, destacou-se: Smartphones, Tablets e computadores com e sem internet. Logo, espera-se que esse estudo, que possibilitou levantar tendências e lacunas sobre o assunto, seja fonte para pesquisas futuras, bem como provoque reflexões sobre os recursos pedagógicos disponíveis para o Ensino de Ciências, especialmente sobre os ODA, que proporcionam dinamismo e aprendizado aos estudantes.
\end{abstract}

Palavras-chave: Aulas de Ciências. Ferramentas tecnológicas. Processo Educativo.

\footnotetext{
${ }^{1}$ Graduação em Ciências Biológicas (UFMT). Especialização em Metodologia do Ensino de Biologia e Química (Faculdade Internacional de Curitiba). Especialização em Redes e Computação (IFMT). Especialização em Educação Especial e Inclusiva e Neuropsicopedagogia (Faculdade Futura). Mestrando no Mestrado Acadêmico em Ensino (IFMT/UNIC), Campus, Cuiabá, Mato Grosso, Brasil. Endereço para correspondência: Avenida São Paulo, 1200-S, Jardim Alvorada, Res. São Paulo III, Bloco 1, Apto. 303, Lucas do Rio Verde, Mato Grosso, Brasil, CEP: 78455-000. E-mail: jeffersonbatistella@ hotmail.com.

${ }^{2}$ Graduação em Química Licenciatura Plena (UNISC) e em Licenciatura em Física (UNEMAT). Especialização em Orientação Educacional (DOM ALBERTO) e em Relações Raciais e Educação na Sociedade Brasileira (UFMT). Mestrado em Ensino (UNIVATES) e Doutorado em Educação em Ciências (UFRGS). Docente permanente do Mestrado Acadêmico em Ensino (IFMT/UNIC). Professor de Química no Departamento de Ensino do IFMT Campus Confresa, Confresa, Mato Grosso, Brasil. Endereço para correspondência: Rua da Paz., 135, Jardim do Éden, Confresa, Mato Grosso, Brasil, CEP: 78.652-000. E-mail: marcelo.leao@ cfs.ifmt.edu.br. 


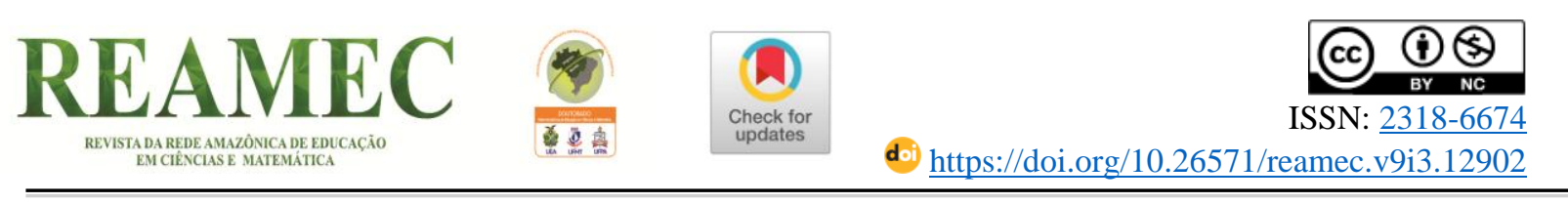

\begin{abstract}
Digital Learning Objects (DLO) have contributed to minimize learning deficits and to virtually reduce the distance between students and teachers in this pandemic period. The study aimed to carry out a survey of scientific production in the last five years (2016-2020) on Digital Learning Objects that are being used in Science Teaching. With regard to methodological procedures, this basic, descriptive and exploratory research, with a qualitative approach, is configured as a state of knowledge. This bibliographic survey of publications considered the last 5 years (2016-2020) as a time frame, and the CAPES Periodical repositories and SciELO as a data source. Of the 398 publications, 23 were selected that were directly related to the topic. It is observed that the use of DLO is more recurrent in Mathematics teaching, whereas in Science teaching its use is focused on practical activities. It was noted that field research and document analysis were the most recurrent types of research and the qualitative approach predominated. The most investigated audiences were teachers and students and the most used DLO were: videos, digital games, teaching platforms, software, google tools and simulators for teaching. The technologies were: Smartphones, Tablets and computers with and without internet. Therefore, it is expected that this research, which made it possible to raise trends and gaps on the subject, will be a source for future research, as well as provoke reflections on the pedagogical resources available for Science Teaching, especially on the ODA, which provide dynamism and learning to students.
\end{abstract}

Keywords: Science Classrooms. Technological Ferramentas. Educational Process.

\title{
RESUMEN
}

Los Objetos de Aprendizaje Digitales (ODA) han contribuido a minimizar los déficits de aprendizaje y a reducir virtualmente la distancia entre estudiantes y profesores en este período pandémico. El estudio tuvo como objetivo realizar un relevamiento de la producción científica en los últimos cinco años (2016-2020) sobre los Objetos Digitales de Aprendizaje que se están utilizando en la Enseñanza de las Ciencias. En cuanto a los procedimientos metodológicos, esta investigación básica, descriptiva y exploratoria, con enfoque cualitativo, se configura como un estado de conocimiento. Este relevamiento bibliográfico de publicaciones consideró los últimos 5 años (2016-2020) como marco temporal, y los repositorios de publicaciones periódicas CAPES y SciELO como fuente de datos. De las 398 publicaciones, se seleccionaron 23 que estaban directamente relacionadas con el tema. Se observa que el uso de la ODA es más recurrente en la enseñanza de las Matemáticas, mientras que en la enseñanza de las Ciencias su uso se centra en actividades prácticas. Se señaló que la investigación de campo y el análisis de documentos eran los más recurrentes y predominaba el enfoque cualitativo. Los públicos más investigados fueron profesores y estudiantes y las ODA más utilizadas fueron: videos, juegos digitales, plataformas de enseñanza, software, herramientas de google y simuladores para la docencia. Las tecnologías fueron: Smartphones, Tablets y ordenadores con y sin internet. Se espera que esta investigación sea una fuente para futuras investigaciones sobre los recursos pedagógicos disponibles para la Enseñanza de las Ciencias, especialmente sobre la AOD, que aportan dinamismo y aprendizaje a los estudiantes.

Palabras clave: Clases de ciencias. Herramientas tecnológicas. Proceso educativo.

\section{INTRODUÇÃO}

Vive-se uma tempestade de mudanças mundiais nos campos da economia, da educação, da saúde, das políticas públicas, das culturas e das tecnologias, em detrimento à 
pandemia provocada pelo Coronavírus. Esse fato, de certa forma, abalou todas as estruturas conhecidas das organizações humanas, o que ocasionou sofrimentos com a perda de milhões de vidas e muitas sequelas físicas e emocionais aos seres humanos. Dessa maneira, os cientistas e a ciência, diante de grandes desafios, foram postos à prova e tiveram, em pouco tempo, que desenvolver possíveis soluções para problemas tão graves nos setores da saúde e, sobretudo, da educação.

Da mesma forma, professores e pesquisadores precisaram quebrar paradigmas educacionais no intuito de minimizar as perdas de aprendizagem de bilhões de pessoas, com a potencialização do uso de ferramentas tecnológicas e/ou Objetos Digitais de Aprendizagem (ODA) na práxis pedagógica, o que mudou consideravelmente o conceito do âmbito escolar, de físico e concreto passou a ser remoto e virtual e gerou transformações no modo de ensinar e aprender, ou seja, um panorama novo sobre o que é educação.

Além disso, lecionar com as novas ferramentas educacionais, principalmente digitais, é uma revolução ao se mudar os paradigmas do ensino, muitas vezes restrito apenas ao giz e apagador, em que somente o professor fala, o que mantém afastados professores e estudantes. Caso contrário, mesmo todos estando imersos aos recursos da modernidade na vida cotidiana, se as práticas educativas não forem atualizadas não será possível modificar o essencial (MORAN, 2000). Nesse viés, vivencia-se o uso demasiado dos ODA, com o intuito de auxiliar no processo de aprendizagem à distância, que se caracteriza como um campo de investigação vasto e de grande interesse dos pesquisadores do âmbito da educação.

O giz e a lousa tiveram o seu papel importante como Objeto de Aprendizado (OA) por um longo período da história para professores e estudantes, mas, atualmente, são os eletrônicos, os aplicativos digitais e a internet das coisas que ocupam o lugar dessas ferramentas. Consequentemente, as Tecnologias Digitais da Informação e Comunicação (TDIC) se tornaram constantes no contexto social e nos ambientes formais e informais de ensino (MORAN, 1995). Ademais, estudos relacionados ao recorte temporal desta pesquisa (2016-2020), sobre os recursos suplementares ao processo educativo, evidenciam que os ODA se destacam no contexto educacional mundial, despontam numa perspectiva crescente no cenário brasileiro e contribuem de forma plausível para que as aulas de Ciências do Ensino Fundamental sejam mais interessantes e favoreçam o ensino desse componente curricular (OLIVEIRA, et al., 2021).

A partir de então, esta pesquisa se iniciou com a perspectiva de compreender as tendências educacionais e colaborar no entendimento, principalmente, dos ODA no Ensino de Ciências. A questão que norteou a realização deste levantamento foi: $\mathrm{O}$ que revela a produção 
científica atual sobre os Objetos Digitais de Aprendizagem voltados para o Ensino de Ciências?

Diante disso, o presente estudo constituiu-se pelas leituras científicas de artigos, livros e dissertações e, posteriormente, reflexões, discussões e possíveis conclusões, além de possibilitar a identificação de lacunas e caminhos a serem explorados em estudos posteriores.

Por fim, esta pesquisa teve como objetivo realizar o levantamento da produção científica, nos últimos cinco anos (2016-2020), sobre os Objetos Digitais de Aprendizagem empregados no Ensino de Ciências.

\section{PRESSUPOSTOS TEÓRICOS SOBRE OBJETOS DIGITAIS DE APRENDIZAGEM}

A tecnologia está no cotidiano de todas as pessoas, o que denota a necessidade de compreender a Cibercultura. A internet das coisas Internet of Things (IoT), em inglês, que domina grande parte das esferas mundiais, envolve setores como o da educação, tecnologia, economia e produção, ou seja, a IoT é um dos maiores sistemas de engenharia da história humana (DEIDMAR; SOBREIRA; LIMA, 2017).

Além disso, o mundo está em constantes mudanças e muitos conhecimentos em tecnologia se tornam obsoletos rapidamente. Entretanto, cabe ressaltar que as TDIC têm contribuído para encurtar as distâncias entre bilhões de pessoas, por meio da maior rede de comunicação, a internet. Para tanto, para entender esse contexto, foi realizado um breve resgate histórico, com o intuito de observar conceitos relevantes.

O uso dos computadores na educação brasileira teve início na década de 70, por meio de experiências em universidades que pertenciam ao grupo da Escola Politécnica da Universidade de São Paulo (USP), de acordo com os Parâmetros Curriculares Nacionais (BRASIL, 2000). Em 1971- O Conselho de Reitores das Universidades Brasileiras promoveu, no Rio de Janeiro, a primeira Conferência Nacional de Tecnologia em Educação Aplicada ao Ensino Superior; Em 1981- Primeiro e segundo Seminário Nacional de Informática em Educação; Em 1989- Construção e aplicação do Plano Nacional de Informática Educativa (PRONINFE) implantado na Secretaria Geral do MEC; Em 1997- Programa Nacional de Informática na Educação (PROINFO), vinculado à Secretaria de Educação a Distância (SEED), do MEC; Em 2000- Obtidos 2.078 computadores para 180 escolas, além da capacitação de recursos humanos e adequação das infraestruturas do programa ao suporte de Educação a Distância e da TV Escola; Em 2003- Simpósio Brasileiro de Informática na Educação (SBI); E em 2006- Projeto UCA - O Governo Federal visou distribuir a cada 
estudante da Rede Pública do Ensino Básico Brasileiro um laptop voltado à educação até 2010.

Assim, a história dos computadores é uma questão relevante para entender a comunicação contemporânea (BRIGGS; BURKE, 2004). Nessa perspectiva, como a história da informática na educação brasileira tem uma inter-relação com a maior rede de comunicação mundial, faz-se necessário compreender um pouco desse processo.

O histórico da internet se iniciou em meados de 1960 com a Guerra Fria, com o Departamento de Defesa dos Estados Unidos (USA), que desenvolveu a Advanced Research Projects Agency (ARPA) e seu principal projeto foi a Arpanet. Para Rodrigues (2008), essa rede reunia os computadores destinados às universidades e às organizações militares para compartilhamento de conhecimento e recursos, principalmente, para projetos estratégicomilitares.

No contexto de 1970 e 1980, a internet se tornou um importante meio de ensino e aprendizado acadêmico, principalmente, nos Estados Unidos. Nessa lógica, Rodrigues (2008, p. 1) afirma que "a internet adotou o protocolo aberto TCP/IP para conectar sistemas heterogêneos, ampliou a dimensão da rede, que passou a se comunicar com equipamentos de diferentes portes, como micros, workstations, mainframes e supercomputadores".

Na sequência, nos anos de 1990 surgiram vários navegadores, o Internet Explorer, o Mozilla Firefox e o Netscape, fortaleceram a internet, a qual passou a ser considerada a maior criação tecnológica de todas as décadas. Logo, a rede aberta de computadores se tornou bem mais ampla e acessível à população. Como afirma Briggs e Burke (2004, p. 310),

[...] o grande avanço aconteceu entre setembro de 1993 e março de 1994, quando uma rede até então dedicada à pesquisa acadêmica se tornou a rede das redes, aberta a todos. No mesmo período, o acesso público a um programa de navegação (Mosaico), descrito na seção de negócios do New York Times de dezembro de 1993 como a 'primeira janela para o ciberespaço', tornou possível atrair usuários - na época chamados 'adaptadores' - e provedores, os pioneiros sem programas.

Entende-se que a internet se iniciou no Brasil em 1988, momento em que o Laboratório Nacional de Computação Científica (LNCC) se conectou à Universidade de Maryland nos Estados Unidos, por meio da Because it's Time of Network (BITNET). Essa rede proporcionava a troca de mensagens, principalmente, de estudantes e professores da Fundação de Amparo à Pesquisa do Estado de São Paulo (FAPESP), em proximidade com a Universidade Estadual do Rio de Janeiro (UERJ), ao possuir entrada à rede da Fermi National Accelerator Laboratory (Fermilab), em Chicago e, em 1989, a Universidade Federal do Rio 
de Janeiro (UFRJ) se uniu à rede BITNET em conjunto com outra universidade americana, a Maryland.

Assim, em 1990, aos poucos, a internet mundial, junto ao interesse comercial, se tornou mais acessível à população. Logo, no contexto atual, nota-se que essa rede está inserida na maioria dos objetos e presente em praticamente todos os lugares, o que ocorre também no âmbito escolar. Ademais, com o surgimento da internet, presencia-se uma nova era, em que as pessoas são dependentes dessa tecnologia.

Juntamente com a história dos computadores e da internet, é importante observar os Objetos de Aprendizagem (OA), uma ferramenta importante para melhorar a aprendizado no que concerne ao Ensino de Ciências e que pode ser utilizado no entendimento de vários componentes curriculares da Base Nacional Comum Curricular (BNCC), no Ensino Fundamental. Além disso, o modo com que esses objetos são utilizados, ou seja, a metodologia com a qual o professor agregará o conteúdo com os OA poderá influenciar para que as aulas fiquem mais dinâmicas e atrativas, tanto visual quanto sonoramente. Isso pode proporcionar um ambiente mais favorável didaticamente, pois possibilita que os estudantes compreendam determinados conteúdos com maior facilidade.

Cabe evidenciar que o conceito de OA surgiu em 1990, porém passou a ser utilizado como materiais didáticos somente em 2000 para melhorar o processo educativo (CARNEIRO; SILVEIRA, 2012). Destaca-se que são muitas as definiçõoes e conceitos sobre OA, e, por isso, aponta-se, na sequência, o entendimento mais apropriado sobre esse recurso.

De acordo com Carneiro e Silveira (2012), o conceito OA é empregado para materiais didáticos feitos para apoio aos processos de ensino e aprendizagem. Já Wiley (2000) descreve que OA é qualquer recurso digital que possa ser reutilizado como apoio à aprendizagem. Outrossim, para Farinelli (2007), os OA são instrumentos que propiciam seu reuso e seu suporte ativo à aprendizagem, avaliado e aprovado pelo ponto de vista especializado e pedagógico da educação.

Nesse viés, para Brasil (2007), os OA são propostas de multimídias interativas com animações, simulações, em que se pode testar diferentes hipóteses, mostrar a evolução temporal, causa e efeito, mentalizar conceitos de distintos entendimentos, ou seja, são ferramentas importantes para despertar a curiosidade e tentar solucionar problemas. Além dos conceitos mencionados, observa-se que teóricos também se utilizaram de metáforas para explicar os $\mathrm{OA}$, os quais são vistos como blocos encaixáveis, podem ser armados e desarmados, além de formar várias estruturas sem perder suas essências originais (TAROUCO, 2012; AGUIAR; FLÔRES, 2014). 
Ademais, Hodgins (2002) trouxe os conceitos dos blocos de LEGO para demonstrar o reuso de um objeto de aprendizagem, para possibilitar o ensino conforme as características de cada estudante. Dessa forma, após a observação de vários conceitos sobre OA, entende-se que se trata de ferramentas pedagógicas ou instrumentos digitais ou não digitais que o professor pode utilizar para facilitar o processo educativo.

Outro aspecto a ser considerado é que as TDIC possuem ferramentas que têm auxiliado e contribuído com o professor na substituição de ferramentas obsoletas utilizadas na educação. Neste momento pandêmico, os ODA, um importante aliado das TDIC, são recursos pedagógicos que merecem destaque, pois são amplamente utilizados nas práticas educacionais para melhoria nos atos de ensinar e aprender (OLIVEIRA, et al., 2021).

Do mesmo modo que os OA, os ODA possuem muitas definições, mas para este estudo foram selecionados alguns teóricos de referência na temática. De acordo com Aguiar e Flôres (2014), os ODA se mostram como recursos favoráveis ao processo educativo de variados componentes curriculares. Outrossim, Tarouco (2012) afirma que ODA são blocos de aprendizagem, modulares e reutilizáveis, idealizados para distribuição e acesso à internet.

Para Tallei e Silva (2016), os ODA são instrumentos digitais reutilizáveis para o processo de aprendizagem, classificados em ferramentas ou aplicações como: animações, aplicativo móvel, apresentação multimídia, áudio, aula digital, simulado e software.

De acordo com Martins (2013), a utilização de ODA geram entusiasmo e colaboram para o entendimento dos conteúdos e para a construção do conhecimento, com a mediação do professor. Nesse viés, os ODA contribuem para a educação, principalmente por sua multiplicidade disciplinar e avaliativa, além de poder ser associado a outros instrumentos educacionais.

Infere-se, assim, que os ODA permitem criar situações que possibilitam a integração dos componentes curriculares e mostram sentido aos conteúdos ministrados, pois como esse recurso é multimídia, permite experiências de resolução de problemas que, de outro modo, dificilmente poderiam ser realizadas (AGUIAR; FLÔRES, 2014). Nesse aspecto, Brasileiro e Silva (2015, p. 41) relatam que:

[...] as simulações computacionais têm demonstrado ser uma ferramenta útil, pois possibilitam não somente a reprodução de fenômenos difíceis de realizar em sala de aula, mas, também, a visualização de fenômenos em escala submicroscópica, trazendo para o concreto situações que demandam um elevado grau de abstração.

A partir do exposto, compreende-se que se pode utilizar os ODA no Ensino de Ciências nos vários conteúdos, para que as aulas se tornem mais atrativas e prazerosas, além 
de permitir que o estudante possa desvendar e entender, de forma mais rápida e simples, os conceitos básicos dos componentes curriculares das Ciências Naturais, além de facilitar o processo de aprendizagem. Dessa forma, os ODA possibilitam que os estudantes testem hipóteses e explorem os conteúdos (BRASILEIRO; SILVA, 2015).

Nessa pensar, Tarouco (2012) ressalta que, para favorecer a construção de novos conhecimentos, os ODA precisam ser dinâmicos, flexíveis, interativos, customizados e fáceis de atualizar. Para o autor, esses objetos são capazes de envolver os estudantes efetivamente em suas aprendizagens para que possam produzir seus conhecimentos, por meio da manipulação dos ODA, de forma física e cognitiva e, assim, possam reconhecer os efeitos de sua própria interação.

Por fim, cabe aqui destacar que alguns ODA, amplamente utilizados no âmbito da Educação Básica pelos professores no Ensino de Ciências para auxiliar na aprendizagem dos estudantes, são os vídeos do Youtube, os simuladores computacionais, a exemplo dos PhET Colorado, os games educativos, entre tantos outros.

\section{PROCEDIMENTOS METODOLÓGICOS}

No intuito de realizar o levantamento da produção científica dos últimos cinco anos sobre os ODA empregados no Ensino de Ciências, o presente estudo configura-se como uma pesquisa bibliográfica, do tipo revisão de literatura, básica, descritiva, exploratória e de abordagem qualitativa.

De acordo com Gil (2017), a pesquisa exploratória proporciona melhor compreensão do problema com possibilidade de torná-lo mais explícito ou construir hipóteses. De forma semelhante, Mattar (2001) pondera que os procedimentos empregados por esse tipo de pesquisa são amplos e versáteis.

Ademais, para Gil (2017), a abordagem qualitativa propicia o aprofundamento da pesquisa dos pontos relacionadas ao fenômeno em estudo e das suas interações. Entretanto, aberta para identificar a individualidade e os significados múltiplos. Nesse viés, de acordo Triviños (1987), a abordagem de evidência qualitativa analisa os dados, busca seu significado e tem a percepção do fenômeno dentro de cada contexto, ou seja, o uso da descrição qualitativa procura entender o fenômeno e também suas essências.

Outrossim, para estudos do tipo revisão de literatura, faz-se necessário delimitar o recorte temporal e a fonte de informações. Por meio das análises e discussões de resultados que esse tipo de pesquisa possibilita, é possível encontrar as lacunas, as tendências 
metodológicas, as práticas educacionais atuais e, no caso, os ODA mais utilizados no Ensino de Ciências.

De acordo com Morosini (2014), esse tipo de estudo possibilita uma síntese da produção científica sobre uma temática específica. Nesse pensar, estreitar e estudar o recorte temporal em relação ao tema de estudo favorecem os registros e as estruturações de dados, os quais mostram-se as ponderações e sínteses sobre as produções científicas atuais.

Salienta-se que a pesquisa se iniciou com a leitura de autores basilares e secundários, com a intenção de fundamentar este estudo. Realizou-se, em seguida, o levantamento bibliográfico em livros, além da análise de artigos e dissertações. Para tanto, escolheu-se os bancos de dados de publicações científicas da Coordenação de Aperfeiçoamento de Pessoal de Nível Superior (CAPES) e O Scientific Electronic Library Online (SciELO).

Além disso, utilizou-se os seguintes descritores de busca: Objetos digitais de aprendizagem no Ensino de Ciências e Objetos digitais de aprendizagem e, na sequência, definiu-se o filtro para os últimos 5 anos (2016-2020) de publicações científicas. Cabe ressaltar que a determinação da fonte, do recorte temporal, dos critérios de inclusão e exclusão para seleção dos textos são fundamentais para esse tipo de pesquisa bibliográfica (MOROSINI, 2014).

Após a utilização dos filtros, encontrou-se 398 publicações, das quais foram selecionadas 23 que estão em consonância com o tema da pesquisa. A identificação e análise para seleção e estudo inclui três etapas: 1) leitura dos títulos, resumos e palavras-chave; 2) download dos textos que contemplavam o escopo do estudo; 3 ) leitura na íntegra dos artigos. Essa leitura mais aprofundada permitiu identificar características da produção científica sobre o assunto. Logo após, organizou-se os resultados da pesquisa, observou-se as abordagens emergentes e suas propriedades metodológicas, bem como lacunas e áreas e conceitos não comtemplados nos estudos, o que poderá contribuir para pesquisas futuras.

Em seguida, considerou-se os seguintes critérios nas publicações selecionadas: temática/assunto; tipo de pesquisa/abordagem; público envolvido/campo de investigação; principais referências; tipos de ODA; tecnologia/materiais necessários; metodologia de ensino; e principais resultados. Ressalta-se que esses critérios de análise e tabulação seguiram orientações de Bardin (2016), de acordo com a técnica denominada Análise de Conteúdo.

Essa maneira de categorização pré-estabelecida, a qual envolve critérios de interpretação e classificação de dados por agrupamento é uma das maneiras indicadas pela técnica de análise escolhida, sendo que a utilização dessas categorias foram estipuladas por esses pesquisadores, ou seja, se a análise fosse realizada por outra pessoa, provavelmente 
teriam essas ou outras características sobre o mesmo material, pois isso varia de acordo com a interpretação subjetiva de cada pesquisador.

\section{RESULTADOS E DISCUSSÃO}

Os dados e informações analisados foram sintetizados e organizados em duas partes, conforme mostram os Quadros 1 e 2.

Quadro 1 - Síntese e caracterização da produção científica analisada no estudo.

\begin{tabular}{|c|c|c|c|c|}
\hline $\begin{array}{c}\text { Estudo } \\
\text { (autor/ano) }\end{array}$ & Temática/Assunto & $\begin{array}{c}\text { Tipo de } \\
\text { Pesquisa/ } \\
\text { Abordagem }\end{array}$ & $\begin{array}{c}\text { Público } \\
\text { envolvido } \\
\text { e Campo de } \\
\text { investigação } \\
\end{array}$ & Referências \\
\hline $\begin{array}{l}\text { Corrêa et al. } \\
(2020)\end{array}$ & $\begin{array}{l}\text { As TDIC como } \\
\text { ferramenta pedagógica. }\end{array}$ & $\begin{array}{l}\text { Qualitativa, } \\
\text { aplicação de } \\
\text { questionário. }\end{array}$ & $\begin{array}{l}\text { Professores e } \\
\text { estudantes do } 2^{\circ} \\
\text { ano do Ensino } \\
\text { Médio. }\end{array}$ & $\begin{array}{l}\text { Costa \& Souza } \\
\text { (2017), Silva (2016), } \\
\text { Lorenzi G. \& Pádua } \\
\text { T. (2012); Rodrigues } \\
\text { E. V. \& Lavino, D. } \\
(2020) \text {. }\end{array}$ \\
\hline $\begin{array}{l}\text { Gouveia e Silva } \\
(2020)\end{array}$ & $\begin{array}{l}\text { Em defesa } \\
\text { infocomunicação. }\end{array}$ & $\begin{array}{l}\text { Qualitativa, } \\
\text { documental, } \\
\text { exploratório } \\
\text { sistemático. }\end{array}$ & $\begin{array}{l}\text { Estudante de um } \\
\text { curso de } \\
\text { Epistemologia, } \\
\text { Prática. } \\
\text { Workshop de } \\
\text { Pós-graduação } \\
\text { em Ciências. }\end{array}$ & $\begin{array}{l}\text { Gouveia, Gaio e } \\
\text { Ranito (2004). } \\
\text { Capurro e Hjørland } \\
(2007) .\end{array}$ \\
\hline $\begin{array}{l}\text { Silva e Ferraz } \\
\text { (2019) }\end{array}$ & $\begin{array}{lr}\text { Jogos digitais no ensino } \\
\text { de matemática para } \\
\text { estudantes } & \text { com } \\
\text { Deficiência } & \text { Intelectual } \\
\text { (DI). } & \end{array}$ & $\begin{array}{l}\text { Qualitativa de } \\
\text { cunho } \\
\text { documental, } \\
\text { estudo do estado } \\
\text { da arte. }\end{array}$ & $\begin{array}{l}\text { Produção } \\
\text { científica } \\
\text { acadêmica dos } \\
\text { professores de } \\
\text { Matemática. }\end{array}$ & $\begin{array}{l}\text { Souza (2015) e Pedro } \\
\text { (2016), Carneiro e } \\
\text { Costa (2017), } \\
\text { Signoretti e Paradeda } \\
\text { (2017). }\end{array}$ \\
\hline $\begin{array}{l}\text { Felcher, Pinto e } \\
\text { Folmer (2019) }\end{array}$ & $\begin{array}{l}\text { Tendências em TDIC no } \\
\text { ensino da Matemática. }\end{array}$ & $\begin{array}{l}\text { Qualitativa, } \\
\text { estado da arte e } \\
\text { da meta-análise. }\end{array}$ & $\begin{array}{l}\text { Estudantes e } \\
\text { Professores de } \\
\text { Pós-Graduação } \\
\text { em Educação } \\
\text { Matemática. }\end{array}$ & $\begin{array}{l}\text { Borba e Penteado } \\
\text { (2012), Silva (2014), } \\
\text { Teixeira (2015), } \\
\text { Gadanidis (2015). }\end{array}$ \\
\hline $\begin{array}{l}\text { Cardoso e } \\
\text { Sampaio (2019) }\end{array}$ & $\begin{array}{l}\text { Uso da informática na } \\
\text { prática docente } \\
\text { matemática. }\end{array}$ & $\begin{array}{l}\text { Pesquisa } \\
\text { Exploratória, } \\
\text { elaboração de } \\
\text { questionário } \\
\text { (escala Likert). }\end{array}$ & $\begin{array}{l}\text { Professores de } \\
\text { matemática do } \\
\text { Ensino } \\
\text { Fundamental. }\end{array}$ & $\begin{array}{l}\text { Barcelos, Passerino, } \\
\text { Behar (2010); Souza; } \\
\text { (2016), Cunha, } \\
\text { Tonetti, Sanavria } \\
\text { (2016). }\end{array}$ \\
\hline $\begin{array}{l}\text { Kaminski, } \\
\text { Ribeiro, } \\
\text { Junkerfeurbom, } \\
\text { Lübeck, } \\
\text { Boscarioli } \\
(2019) \\
\end{array}$ & $\begin{array}{l}\text { Utilização de jogos } \\
\text { digitais em aulas de } \\
\text { Matemática. }\end{array}$ & $\begin{array}{l}\text { Qualitativa e } \\
\text { Exploratória. }\end{array}$ & $\begin{array}{l}\text { Estudantes do } 5^{\circ} \\
\text { ano e do } 6^{\circ} \text { ano } \\
\text { do Ensino } \\
\text { Fundamental de } \\
\text { uma escola } \\
\text { indígena. }\end{array}$ & $\begin{array}{l}\text { Cruz (2006), } \\
\text { Clarindo e Barboza } \\
(2010), \text { Ilha e Cruz } \\
\text { (2006), Gonçalves } \\
\text { (2011), Moran e } \\
\text { Bacich (2015). }\end{array}$ \\
\hline $\begin{array}{l}\text { Perfetto e } \\
\text { Buquerque } \\
(2018) \\
\end{array}$ & $\begin{array}{l}\text { Objeto Virtuais de } \\
\text { Aprendizagem (OVA). }\end{array}$ & $\begin{array}{l}\text { Qualitativa, } \\
\text { Básica, } \\
\text { Exploratória. }\end{array}$ & $\begin{array}{l}\text { Suporte aos } \\
\text { professores. }\end{array}$ & $\begin{array}{l}\text { Wiley (2000), Braga } \\
\text { (2014), Pimentel e } \\
\text { Dotta, 2013). }\end{array}$ \\
\hline $\begin{array}{l}\text { Macêdo e } \\
\text { Voelzke (2020) }\end{array}$ & $\begin{array}{l}\text { OA utilizados no ensino } \\
\text { de astronomia. }\end{array}$ & $\begin{array}{l}\text { Abordagem } \\
\text { qualitativa. }\end{array}$ & $\begin{array}{l}\text { Estudantes de } \\
\text { licenciaturas em }\end{array}$ & $\begin{array}{l}\text { Oliveira Filho e } \\
\text { Saraiva (2017), Faria }\end{array}$ \\
\hline
\end{tabular}




\begin{tabular}{|c|c|c|c|c|}
\hline & & & $\begin{array}{l}\text { Física, } \\
\text { Matemática e } \\
\text { Biologia. }\end{array}$ & $\begin{array}{l}\text { (2007), Ridpath } \\
\text { (2007), Nogueira } \\
\text { (2009). }\end{array}$ \\
\hline $\begin{array}{l}\text { Danhão, } \\
\text { Frenedozo, } \\
\text { Schimiguel e } \\
\text { Coelho (2019) }\end{array}$ & $\begin{array}{l}\text { Influência de ODA no } \\
\text { processo educacional. }\end{array}$ & $\begin{array}{l}\text { Qualitativa e } \\
\text { Exploratória. }\end{array}$ & $\begin{array}{l}\text { Dez estudantes } \\
\text { do curso de } \\
\text { Biologia e } \\
\text { Biotecnologia } \\
\text { Portugal. }\end{array}$ & $\begin{array}{l}\text { Kenski (2012), Bittar } \\
\text { (2006), Lopes (2018), } \\
\text { Motta e Angotti } \\
\text { (2011), Wiley (2001). }\end{array}$ \\
\hline $\begin{array}{l}\text { Fujita e } \\
\text { Rodrigues } \\
\text { (2016) }\end{array}$ & $\begin{array}{l}\text { Alternativas } \\
\text { metodológicas e } \\
\text { estratégias didáticas } \\
\text { utilizadas na matemática. }\end{array}$ & $\begin{array}{l}\text { Abordagem } \\
\text { qualitativa } \\
\text { exploratória, } \\
\text { estudo de } \\
\text { campo. }\end{array}$ & $\begin{array}{l}\text { Professores da } \\
\text { Rede Estadual de } \\
\text { São Paulo. }\end{array}$ & $\begin{array}{l}\text { Lins (1997), } \\
\text { Sadovsky (2007), } \\
\text { Fernandes (2011), } \\
\text { Tufano (2004). }\end{array}$ \\
\hline Gomes (2017) & $\begin{array}{l}\text { Análise linguística, } \\
\text { ensino e letramento } \\
\text { digital. }\end{array}$ & $\begin{array}{l}\text { Análise } \\
\text { documental, na } \\
\text { perspectiva da } \\
\text { abordagem } \\
\text { qualitativo- } \\
\text { interpretativista. }\end{array}$ & $\begin{array}{l}\text { Dados analisados } \\
\text { de um Doutorado } \\
\text { (em andamento). } \\
\text { Estudantes e } \\
\text { Professores. }\end{array}$ & $\begin{array}{l}\text { Araújo (2013), } \\
\text { Santaella, (2003, } \\
\text { 2004), Cope, } \\
\text { Kalantzis (2000), } \\
\text { Rojo e Moura (2012) } \\
\text { Rojo (2013) } \\
\text { Lankshear, Knobel } \\
\text { (2007). }\end{array}$ \\
\hline $\begin{array}{l}\text { Oliveira, } \\
\text { Carvalho, } \\
\text { Kapitango-a- } \\
\text { Samba (2019) }\end{array}$ & $\begin{array}{l}\text { Possibilidades e } \\
\text { limitações de ODA. }\end{array}$ & $\begin{array}{l}\text { Pesquisa } \\
\text { empírica, } \\
\text { qualitativa, uso } \\
\text { de entrevista } \\
\text { estruturada. }\end{array}$ & $\begin{array}{l}\text { Estudantes do } \\
\text { Ensino Médio, } \\
\text { de uma Escola } \\
\text { pública Estadual } \\
\text { de Mato Grosso. }\end{array}$ & $\begin{array}{l}\text { Giordan (2008), Paz } \\
\text { (2007), Brasileiro; } \\
\text { Silva (2015), } \\
\text { Nascimento (2010), } \\
\text { Cirino; Souza (2009), } \\
\text { Oliveira (2017), } \\
\text { Aguiar, Barreto; } \\
\text { Flôres, Pozzatti } \\
\text { (2014). }\end{array}$ \\
\hline $\begin{array}{l}\text { Martins, } \\
\text { Forneck, Diesel, } \\
\text { Bublitz (2016) }\end{array}$ & $\begin{array}{l}\text { O uso de ODA para o } \\
\text { aprimoramento da } \\
\text { compreensão leitora } \\
\text { metacognitiva. }\end{array}$ & $\begin{array}{l}\text { Abordagem } \\
\text { quantitativa, } \\
\text { metodologias de } \\
\text { ensino ativo. } \\
\end{array}$ & $\begin{array}{l}42 \text { estudantes } \\
\text { brasileiros do } 8^{\circ} \\
\text { ano do Ensino } \\
\text { Fundamental. } \\
\end{array}$ & $\begin{array}{l}\text { Morán (2015), } \\
\text { Ferreira (2010), } \\
\text { Mogilka (1999) } \\
\text { eTarouco (2012). }\end{array}$ \\
\hline $\begin{array}{l}\text { Alexandre e } \\
\text { Barros (2020) }\end{array}$ & $\begin{array}{l}\text { Critérios avaliativos dos } \\
\text { ODA e os estilos de uso } \\
\text { do virtual. }\end{array}$ & $\begin{array}{l}\text { Qualitativo por } \\
\text { meio de uma } \\
\text { pesquisa } \\
\text { exploratória e } \\
\text { analítica. }\end{array}$ & $\begin{array}{l}\text { Estudantes de } \\
\text { Pós-graduaçãa, } \\
\text { Mestrado } \\
\text { Educação para a } \\
\text { Ciência da } \\
\text { Universidade } \\
\text { Estadual Paulista. }\end{array}$ & $\begin{array}{l}\text { Alexandre }(2017), \\
\text { Barros }(2008,2009) . \\
\text { Deleuze }(1996) \mathrm{e} \\
\text { Lévy }(1996,2009), \\
\text { Castells }(1999,2020) \text {, } \\
\text { Lankshear. }(2003) .\end{array}$ \\
\hline $\begin{array}{l}\text { Chinaglia e } \\
\text { Mendonça } \\
\text { (2017) }\end{array}$ & $\begin{array}{l}\text { Panorama de materiais } \\
\text { didáticos para o uso de } \\
\text { novas tecnologias na } \\
\text { escola. }\end{array}$ & $\begin{array}{l}\text { Estudo } \\
\text { exploratório, } \\
\text { básico, } \\
\text { aplicação de } \\
\text { questionário. }\end{array}$ & $\begin{array}{l}\text { Estudantes de } \\
\text { Pós-Graduação } \\
\text { em Linguistica } \\
\text { Aplicada da } \\
\text { UECE. }\end{array}$ & $\begin{array}{l}\text { Santaella (2010), } \\
\text { Lemke, (2010), } \\
\text { Almeida (2014), } \\
\text { Leffa (2006). }\end{array}$ \\
\hline $\begin{array}{l}\text { Alves, Velho e } \\
\text { Barwaldt (2016) }\end{array}$ & Investigação dos ODA. & $\begin{array}{l}\text { Qualitativa, } \\
\text { estudo } \\
\text { exploratório, } \\
\text { básica, } \\
\text { questionário e } \\
\text { entrevistas. }\end{array}$ & $\begin{array}{l}\text { Estudantes e } \\
\text { professores do } 4^{\circ} \\
\text { ano do Ensino } \\
\text { Fundamental. } \\
\text { Uma Escola } \\
\text { Estadual de Porto } \\
\text { Alegre. }\end{array}$ & $\begin{array}{l}\text { Prensky (2001), Lévy } \\
\text { (1999), Tarouco, } \\
\text { (2006), Valente } \\
(2008), \\
\text { Lemos e Moura } \\
\text { (2000), Kishimoto } \\
\text { (1996), Galego } \\
(2007) .\end{array}$ \\
\hline $\begin{array}{l}\text { Camillo e } \\
\text { Medeiros (2018) }\end{array}$ & $\begin{array}{l}\text { A utilização de jogos na } \\
\text { educação. }\end{array}$ & $\begin{array}{l}\text { Revisão } \\
\text { sistemática, } \\
\text { qualitativa. }\end{array}$ & $\begin{array}{l}\text { Artigos da } \\
\text { Revista } \\
\text { RENOTE. }\end{array}$ & $\begin{array}{l}\text { Prensky (2002), } \\
\text { Schneider (2017), } \\
\text { Santaella (2009, } \\
\text { 2013), Poltronieri } \\
\text { (2009) e Stahl (1991). }\end{array}$ \\
\hline Oliveira, & Os OA podem ser & Revisão & Dissertações na & Aguiar e Flores \\
\hline
\end{tabular}




\begin{tabular}{|c|c|c|c|c|}
\hline $\begin{array}{l}\text { Coelho Neto } \\
\text { (2019) }\end{array}$ & $\begin{array}{l}\text { poderosos instrumentos } \\
\text { digitais educacionais. }\end{array}$ & $\begin{array}{l}\text { Sistemática de } \\
\text { Literatura, } \\
\text { qualitativa. }\end{array}$ & área de Ensino. & $\begin{array}{l}\text { (2014), Wiley (2000), } \\
\text { Ramos (2016), } \\
\text { Silveira (2006) e } \\
\text { Morais (2010) }\end{array}$ \\
\hline Silva (2020) & $\begin{array}{l}\text { Gêneros digitais e } \\
\text { alfabetização. }\end{array}$ & $\begin{array}{l}\text { Pesquisa de } \\
\text { abordagem } \\
\text { qualitativa, } \\
\text { perspectiva } \\
\text { descritiva. }\end{array}$ & $\begin{array}{l}\text { Professores e } \\
\text { estudantes } \\
\text { Ensino } \\
\text { Fundamental. }\end{array}$ & $\begin{array}{l}\text { Bakhtin (1992), } \\
\text { Marcuschi (2008), } \\
\text { Crystal, d. 2001. } \\
\text { Vergueiro, 2014). }\end{array}$ \\
\hline $\begin{array}{l}\text { Silva, } \\
\text { Rutiquewiski, } \\
\text { Benatti (2018) }\end{array}$ & $\begin{array}{l}\text { Os ODA que } \\
\text { acompanham a coleção } \\
\text { didática Linguagem e } \\
\text { Interação. }\end{array}$ & $\begin{array}{l}\text { Pesquisa } \\
\text { documental } \\
\text { (documentos } \\
\text { oficiais de } \\
\text { ensino) e } \\
\text { bibliográfico. }\end{array}$ & $\begin{array}{l}\text { Estudantes, } \\
\text { OED da Coleção } \\
\text { da editora Ática. }\end{array}$ & $\begin{array}{l}\text { Leffa (2006) Antunes } \\
\text { (2007); Marcuschi } \\
\text { (2008), Dionísio } \\
\text { (2011 e 2014), Rojo, } \\
\text { 2012, 2013 e 2017). }\end{array}$ \\
\hline $\begin{array}{l}\text { Martins e } \\
\text { Piemonte (2018) }\end{array}$ & Ensino Híbrido e ODA. & $\begin{array}{l}\text { Pesquisa } \\
\text { qualitativa } \\
\text { apoiada pela } \\
\text { pesquisa } \\
\text { quantitativa, } \\
\text { observações da } \\
\text { dinâmica em } \\
\text { sala de aula. }\end{array}$ & $\begin{array}{l}\text { Professor de } \\
\text { Biologia, } 61 \\
\text { estudantes } \\
\text { ouvintes e um } \\
\text { surdo do } 1^{\circ} \text { ano } \\
\text { do Ensino Médio } \\
\text { de um colégio do } \\
\text { Paraná. }\end{array}$ & $\begin{array}{l}\text { Bacich, Neto e } \\
\text { Trevisani (2015); } \\
\text { Spinardi, Both } \\
\text { (2018), Martinho, } \\
\text { Pombo (2009); } \\
\text { Mercado, Silva e } \\
\text { Gracindo (2008). }\end{array}$ \\
\hline $\begin{array}{l}\text { Carvalho, } \\
\text { Castro, Maia, } \\
\text { Pinheiro (2016) }\end{array}$ & $\begin{array}{l}\text { Formação de professores } \\
\text { para que possam integrar } \\
\text { as TDIC aos processos } \\
\text { Pedagógicos. }\end{array}$ & $\begin{array}{l}\text { Pesquisa } \\
\text { colaborativa. }\end{array}$ & $\begin{array}{l}\text { Futuros } \\
\text { professores de } \\
\text { Matemática. }\end{array}$ & $\begin{array}{l}\text { Mishra e Koehler } \\
\text { (2006), Almeida } \\
\text { (2008), Mendes } \\
\text { (2009), Borba, } \\
\text { Penteado, Bittar } \\
\text { (2010), Almeida, } \\
\text { Valente (2011). }\end{array}$ \\
\hline $\begin{array}{l}\text { Araujo, Bracho } \\
\text { (2019) }\end{array}$ & $\begin{array}{l}\text { Uso de recursos didáticos } \\
\text { no Ensino das Ciências } \\
\text { com TDIC. }\end{array}$ & $\begin{array}{l}\text { Pesquisa } \\
\text { qualitativa. }\end{array}$ & $\begin{array}{l}\text { Professores e } \\
\text { estudantes. }\end{array}$ & $\begin{array}{l}\text { Kalinke, Derossi, } \\
\text { Janegitz e Nogueira } \\
\text { (2015), Wiley (2000), } \\
\text { Valim, Ribeiro, Silva } \\
\text { e Cascaes (2013). }\end{array}$ \\
\hline
\end{tabular}

Fonte: Elaborado pelos autores (2021).

Diante dos estudos realizados com a temática/assunto abordado fica evidente que os ODA estão diretamente relacionados à práticas pedagógicas, com maior frequência no ensino da Matemática, como se observa nos estudos de Silva e Ferras (2019); Felcher, Pinto e Folmer (2019); Cardoso e Sampaio (2019); Kaminski, Ribeiro, Junkerfeurbom, Lübeck, Boscarioli (2019); Fujita e Rodrigues (2016); Oliveira, Coelho Neto (2019); Carvalho, Castro, Maia, Pinheiro (2016) e Araujo, Bracho (2019).

Relacionados aos componentes curriculares de Ciências Naturais do Ensino Médio, a temática está voltada às experiências e atividades de ensino, a exemplo dos estudos de Corrêa et al. (2020); Macêdo e Voelzke (2020); Danhão, Frenedozo, Schimiguel e Coelho (2019); Oliveira, Carvalho, Kapitango-a-Samba (2019); Martins e Piemonte (2018). Os demais estudos relacionam a temática ODA, de modo geral, à área de educação. Percebe-se, assim, que no Ensino de Ciências no Ensino Fundamental, nesse recorte temporal, não houve nenhuma produção científica, o que enfatiza a importância desta pesquisa. Entretanto, mesmo 
sem compor o recorte temporal definido para essa investigação, cabe ressaltar que o recente estudo de Oliveira et al. (2021) aborda a temática e utilizou o Quilegal como ODA e recurso pedagógico para ensinar Ciências Naturais no Ensino Fundamental.

Além disso, a abordagem de pesquisa predominante nas produções analisadas é a qualitativa com dezenove estudos, apenas 4 pesquisas não se posicionaram claramente quanto à abordagem, mas, diante das análises, pode-se se entender que também são qualitativas. Para Minayo (2008), o método qualitativo é importante para os estudos da história, representações, crenças, das ligações, das percepções e opiniões dos produtos que os humanos fazem durante suas vidas.

No que tange às tendências metodológicas, notam-se, em relação ao objetivo exploratório, que prevalecem as pesquisas do tipo documental e de campo. Quanto aos instrumentos de coleta de dados, há o uso constante de questionários e entrevistas. Outro ponto relevante é o público envolvido na pesquisa que, em sua maioria, são professores e estudantes do Ensino Médio.

Outrossim, no que diz respeito às fundamentações teóricas que explicitam tendências recorrentes nos trabalhos analisados, mostram-se como autores basilares: Almeida (2014); Barros (2008); Lévy (1999); Rojo (2012); Santaella (2003); Tarouco (2006); Valente (2011); Wiley (2000) e os mais recorrentes nas pesquisas atuais são: Aguiar (2014); Almeida (2014); Bacich (2015); Barros (2008, 2009); Bittar (2010); Borba (2012); Costa (2017); Lankshear (2003); Leffa (2006); Lévy (1999), Oliveira (2017), Penteado (2012), Prensky (2002), Rojo (2012, 2013), Santaella, (2003, 2004), Santos (2019), Souza, (2009) e Wiley (2000).

Em síntese, observa-se que é fundamental a investigação científica para embasar as sugestões de estudos na busca de um conhecimento que decorre dos obstáculos existentes, do anseio de produzir novos conhecimentos e transformá-lo ou ampliá-lo (KÖCHE, 2012).

Por conseguinte, notam-se as análises e discussões do Quadro 2.

Quadro 2 - Caracterização da produção científica analisada no estudo.

\begin{tabular}{|l|l|l|l|l|}
\hline \multicolumn{1}{|c|}{$\begin{array}{c}\text { Estudo } \\
\text { (autor/ano) }\end{array}$} & \multicolumn{1}{|c|}{$\begin{array}{c}\text { Tipos de } \\
\text { ODA }\end{array}$} & $\begin{array}{c}\text { Tecnologia/ } \\
\text { Materiais } \\
\text { necessários }\end{array}$ & \multicolumn{1}{|c|}{$\begin{array}{c}\text { Metodologia de } \\
\text { ensino }\end{array}$} & \multicolumn{1}{|c|}{ Principais resultados } \\
\hline $\begin{array}{l}\text { Corrêa, } \\
\text { Martins, } \\
\text { Millan e } \\
\text { Marangon } \\
(\mathbf{2 0 2 0})\end{array}$ & $\begin{array}{l}\text { Vídeos, } \\
\text { animações e } \\
\text { documentário, }\end{array}$ & $\begin{array}{l}\text { Smartphones, } \\
\text { WhatsApp, } \\
\text { Movie Maker. } \\
\text { tecnologia que } \\
\text { possua uma } \\
\text { câmera } \\
\text { filmadora. }\end{array}$ & $\begin{array}{l}\text { Apresentação da } \\
\text { técnica Stop Motion, } \\
\text { oficina, animações e } \\
\text { socialização dos } \\
\text { vídeos. }\end{array}$ & $\begin{array}{l}\text { 6 (seis) micrometragens de } \\
\text { animação. }\end{array}$ \\
\hline $\begin{array}{l}\text { Gouveia e } \\
\text { Silva (2020) }\end{array}$ & Não se aplica. & Não se aplica. & Não se aplica. & $\begin{array}{l}\text { Infocomunicação agrega } \\
\text { construtivamente as Ciências }\end{array}$ \\
\hline
\end{tabular}

Universidade Federal de Mato Grosso, Cuiabá, Mato Grosso, Brasil. Revista REAMEC - Rede Amazônica de Educação em Ciências e Matemática, v. 9, n. 3, e21098, setembro-dezembro, 2021. 


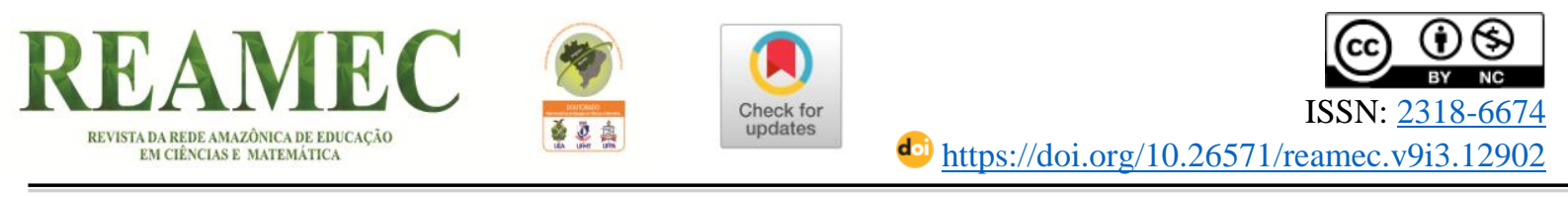

\begin{tabular}{|c|c|c|c|c|}
\hline & & & & $\begin{array}{l}\text { da Informação e da } \\
\text { Comunicação (CIC) e as } \\
\text { estimula a construir } \\
\text { estratégias comuns. }\end{array}$ \\
\hline $\begin{array}{l}\text { Silva e Ferraz } \\
(2019)\end{array}$ & Não se aplica. & Não se aplica. & Não se aplica. & $\begin{array}{l}\text { A utilização dos jogos } \\
\text { digitais colabora para o } \\
\text { aprendizado de estudantes } \\
\text { com deficiência ou não. }\end{array}$ \\
\hline $\begin{array}{l}\text { Felcher, Pinto } \\
\text { e Folmer } \\
(2019) \\
\end{array}$ & Não se aplica. & Não se aplica. & Não se aplica. & $\begin{array}{lcc}\text { Predominam o uso } & \text { do } \\
\text { GeoGebra, } & \text { seguido } & \text { de } \\
\text { vídeos é uma tendência. } & \\
\end{array}$ \\
\hline $\begin{array}{l}\text { Cardoso e } \\
\text { Sampaio } \\
(2019)\end{array}$ & Não se aplica. & Não se aplica. & Não se aplica. & $\begin{array}{l}\text { As ferramentas tecnológicas } \\
\text { na educação podem } \\
\text { potencializar a compreensão } \\
\text { dos estudantes. }\end{array}$ \\
\hline $\begin{array}{l}\text { Kaminski, } \\
\text { Ribeiro, } \\
\text { Junkerfeurbo } \\
\text { m, Lubeck, } \\
\text { Boscarioli } \\
(2019)\end{array}$ & $\begin{array}{l}\text { Jogos digitais: } \\
\text { Game das } \\
\text { Frações e } \\
\text { Labirinto das } \\
\text { Frações. }\end{array}$ & $\begin{array}{l}\text { Computadores, } \\
\text { Notebooks, } \\
\text { calculadoras, } \\
\text { aulas offline e } \\
\text { online. }\end{array}$ & $\begin{array}{l}\text { Explicou-se o jogo, } \\
\text { mostrou o ambiente } \\
\text { inicial do jogo, com } \\
\text { desafio para o } \\
\text { estudante responder } \\
\text { corretamente questões } \\
\text { de matemática. }\end{array}$ & $\begin{array}{l}\text { Percebeu-se que o uso dos } \\
\text { jogos favoreceu o interesse } \\
\text { dos estudantes. }\end{array}$ \\
\hline $\begin{array}{l}\text { Perfetto e } \\
\text { Buquerque } \\
(\mathbf{2 0 1 8 )}\end{array}$ & $\begin{array}{l}\text { Learning } \\
\text { Object Review } \\
\text { Instrument } \\
\text { (LORI) em } \\
\text { sua versão 1.5. }\end{array}$ & Computadores. & Não se aplica. & $\begin{array}{l}\text { OVA possui importância no } \\
\text { âmbito da Organização e } \\
\text { Representação da } \\
\text { Informação. }\end{array}$ \\
\hline $\begin{array}{l}\text { Macêdo e } \\
\text { Voelzke } \\
(\mathbf{2 0 2 0})\end{array}$ & $\begin{array}{l}\text { Software } \\
\text { Stellarium. }\end{array}$ & $\begin{array}{l}\text { Computadores, } \\
\text { offline ou on- } \\
\text { line. }\end{array}$ & $\begin{array}{l}\text { Apresenta atividades } \\
\text { práticas de pesquisa } \\
\text { nos quais os estudantes } \\
\text { demonstram o } \\
\text { conhecimento } \\
\text { adquirido por meio do } \\
\text { Software Stellarium. }\end{array}$ & $\begin{array}{l}\text { Contribuiu para formação } \\
\text { inicial de professores e a } \\
\text { atividade proposta podem } \\
\text { contribuir no ensino de } \\
\text { astronomia. }\end{array}$ \\
\hline $\begin{array}{l}\text { Danhão, } \\
\text { Frenedozo, } \\
\text { Schimiguel e } \\
\text { Coelho }(2019)\end{array}$ & $\begin{array}{l}\text { Google drive, } \\
\text { Google Forms, } \\
\text { Site } \\
\text { Planetabio. }\end{array}$ & $\begin{array}{l}\text { Computadores, } \\
\text { Celulares e } \\
\text { internet. }\end{array}$ & $\begin{array}{l}\text { O site Planetabio foi } \\
\text { utilizado para ajudar no } \\
\text { entendimento do } \\
\text { conteúdo, depois } \\
\text { disponibilizados links } \\
\text { de teste contendo } \\
\text { questões de múltipla. }\end{array}$ & $\begin{array}{l}\text { Melhor desempenho dos } \\
\text { estudantes que utilizaram } \\
\text { ODA. }\end{array}$ \\
\hline $\begin{array}{l}\text { Fujita e } \\
\text { Rodrigues } \\
(2016)\end{array}$ & $\begin{array}{l}\text { Plataforma } \\
\text { educacional } \\
\text { encampa a } \\
\text { filosofia WEB } \\
2.0 \\
\text { (Aprendizage } \\
\text { m } \\
\text { Colaborativa }{ }^{14} \\
\text { ) }\end{array}$ & $\begin{array}{l}\text { Computadores e } \\
\text { internet. }\end{array}$ & $\begin{array}{l}\text { Foi mostrado ao futuro } \\
\text { professor os ODA } \\
\text { disponíveis na } \\
\text { plataforma, os } \\
\text { conteúdos matemáticos } \\
\text { para aplicação em } \\
\text { momentos oportunos. }\end{array}$ & $\begin{array}{l}\text { É indiscutível que a } \\
\text { tecnologia ainda "encanta" e } \\
\text { seduz o estudante em } \\
\text { formação. }\end{array}$ \\
\hline Gomes (2017) & $\begin{array}{l}\text { Plataforma } \\
\text { multimídia, } \\
\text { com imagens, } \\
\text { sons típicos de } \\
\text { uma situação } \\
\text { de jogo } \\
\text { esportivo. }\end{array}$ & $\begin{array}{l}\text { Computadores e } \\
\text { internet. }\end{array}$ & Não se aplica. & $\begin{array}{l}\text { Não há, portanto, novos } \\
\text { letramentos, mas apenas } \\
\text { multiletramentos, por causa } \\
\text { das mídias eletrônicas. }\end{array}$ \\
\hline $\begin{array}{l}\text { Oliveira, } \\
\text { Carvalho, } \\
\text { Kapitango-a- }\end{array}$ & $\begin{array}{l}\text { Softwares: } \\
\text { Chemical } \\
\text { Balance, }\end{array}$ & $\begin{array}{l}\text { Computadores e } \\
\text { Celulares com } \\
\text { internet. }\end{array}$ & $\begin{array}{l}\text { Foram apresentados os } \\
\text { ODA e feitas } \\
\text { explicações sobre o }\end{array}$ & $\begin{array}{l}\text { Permitem demonstrar que os } \\
\text { ODA possuem } \\
\text { possibilidades de motivar e }\end{array}$ \\
\hline
\end{tabular}




\begin{tabular}{|c|c|c|c|c|}
\hline Samba (2019) & $\begin{array}{l}\text { Balanceament } \\
\text { o de Equações } \\
\text { Químicas e } \\
\text { Reagentes } \\
\text { Produtos e } \\
\text { Excesso. } \\
\end{array}$ & & $\begin{array}{l}\text { funcionamento de cada } \\
\text { um deles. Ocorreram } \\
\text { encontros com } \\
\text { entrevistas estruturadas } \\
\text { aos estudantes. }\end{array}$ & $\begin{array}{l}\text { mobilizar conhecimento, } \\
\text { dinamizar o ensino e auxiliar } \\
\text { a aprendizagem. }\end{array}$ \\
\hline $\begin{array}{l}\text { Martins, } \\
\text { Forneck, } \\
\text { Diesel, } \\
\text { Bublitz } \\
(2016)\end{array}$ & $\begin{array}{l}\text { Michaelis on- } \\
\text { line dicionário } \\
(2015) \text {. }\end{array}$ & $\begin{array}{l}\text { Laboratório de } \\
\text { Informática } \\
\text { Escolar e } \\
\text { Computadores } \\
\text { com internet. }\end{array}$ & $\begin{array}{l}\text { Metodologia ativa de } \\
\text { ensino, com os quais se } \\
\text { aplicou uma pré- } \\
\text { testagem com método } \\
\text { cloze e interação com } \\
\text { os ODA. }\end{array}$ & $\begin{array}{l}\text { Evidenciaram o } \\
\text { aprimoramento da } \\
\text { compreensão leitora dos } \\
\text { sujeitos investigados após } \\
\text { utilização dos ODA. }\end{array}$ \\
\hline $\begin{array}{l}\text { Alexandre e } \\
\text { Barros (2020) }\end{array}$ & Não se aplica. & Não se aplica. & Não se aplica. & $\begin{array}{l}\text { Considera-se as } \\
\text { possibilidades de } \\
\text { aprimoramento na } \\
\text { construção de ODA com } \\
\text { parâmetros atuais e de } \\
\text { qualidade que atendam as } \\
\text { tipologias. }\end{array}$ \\
\hline $\begin{array}{l}\text { Chinaglia e } \\
\text { Mendonça } \\
(2017)\end{array}$ & $\begin{array}{l}\text { Lara Croft, } \\
\text { Google, } \\
\text { Google Maps, } \\
\text { Google } \\
\text { Docs, Easely. }\end{array}$ & $\begin{array}{l}\text { Computadores e } \\
\text { internet. }\end{array}$ & $\begin{array}{l}\text { Perspectiva de um } \\
\text { Webcurrículo falante } \\
\text { numa atmosfera gamer. }\end{array}$ & $\begin{array}{l}\text { Evidenciar possíveis } \\
\text { caminhos a serem seguidos } \\
\text { na construção de um } \\
\text { material didático para os } \\
\text { multiletramentos. }\end{array}$ \\
\hline $\begin{array}{l}\text { Alves, Velho } \\
\text { e Barwaldt } \\
(\mathbf{2 0 1 6 )}\end{array}$ & $\begin{array}{l}\text { Vídeo, jogos e } \\
\text { sites como } \\
\text { construção do } \\
\text { livro digital. }\end{array}$ & $\begin{array}{l}\text { Laboratório de } \\
\text { Informática, } \\
\text { com internet. }\end{array}$ & $\begin{array}{l}\text { Brincando com os } \\
\text { números. } \\
\text { Pesquisa de dados. } \\
\text { Apresentação e troca } \\
\text { de saberes, } \\
\text { Contextualização e } \\
\text { sistematização do } \\
\text { conhecimento } \\
\text { trabalhado. }\end{array}$ & $\begin{array}{l}\text { Concluiu-se que o uso das } \\
\text { TDIC apresentou significado } \\
\text { importante no processo de } \\
\text { ensino e aprendizagem. }\end{array}$ \\
\hline $\begin{array}{l}\text { Camillo e } \\
\text { Medeiros } \\
(\mathbf{2 0 1 8})\end{array}$ & Não se aplica. & Não se aplica. & $\begin{array}{l}\text { São apresentados os } \\
\text { estudos realizados no } \\
\text { período entre } 2010 \text { a } \\
2016 \text { na Revista } \\
\text { RENOTE. }\end{array}$ & $\begin{array}{l}\text { A importância dos jogos } \\
\text { educacionais no ambiente } \\
\text { escolar. Retrataram-se a } \\
\text { aceitação e a motivação dos } \\
\text { estudantes quando utilizam } \\
\text { jogos educativos } \\
\end{array}$ \\
\hline $\begin{array}{l}\text { Oliveira e } \\
\text { Coelho Neto } \\
(2019)\end{array}$ & Não se aplica & Não se aplica & $\begin{array}{l}\text { As dissertações dos } \\
\text { programas } \\
\text { profissionais de pós- } \\
\text { graduação na área de } \\
\text { Ensino, listados na } \\
\text { plataforma Sucupira. }\end{array}$ & $\begin{array}{l}\text { A necessidade de pesquisas } \\
\text { sobre a potencialidade do } \\
\text { uso das TDIC, } \\
\text { principalmente os OA. }\end{array}$ \\
\hline Silva (2020) & $\begin{array}{l}\text { Softwares e } \\
\text { plataformas } \\
\text { digitais, site } \\
\text { Comic } \\
\text { Creator } \\
\text { template, site } \\
\text { Stripcreator, } \\
\text { HagáQuê. }\end{array}$ & $\begin{array}{l}\text { Computadores } \\
\text { ou em outros } \\
\text { dispositivos } \\
\text { eletrônicos que } \\
\text { possua internet. }\end{array}$ & $\begin{array}{l}\text { Produção de histórias } \\
\text { em quadrinhos } \\
\text { utilizando ferramentas } \\
\text { digitais ou de softwares } \\
\text { que facilitam a } \\
\text { elaboração de histórias. }\end{array}$ & $\begin{array}{l}\text { Alguns softwares } \\
\text { plenamente possíveis de } \\
\text { serem utilizados na escola } \\
\text { para o trabalho produtivo } \\
\text { com o gênero digital história } \\
\text { em quadrinho em turmas de } \\
\text { alfabetização. }\end{array}$ \\
\hline $\begin{array}{l}\text { Silva, } \\
\text { Rutiquewiski, } \\
\text { Benatti } \\
\text { (2018) }\end{array}$ & $\begin{array}{l}\text { Plataforma } \\
\text { digital, com } \\
\text { suporte de } \\
\text { livros e } \\
\text { atividades. }\end{array}$ & $\begin{array}{l}\text { Computadores } \\
\text { ou tablete e } \\
\text { celulares que } \\
\text { tenha acesso à } \\
\text { internet. }\end{array}$ & Não se aplica. & $\begin{array}{l}\text { Os OED são satisfatórios ao } \\
\text { ensino de } \\
\text { Língua, deixa a desejar } \\
\text { quanto ao desenvolvimento } \\
\text { das habilidades linguísticas } \\
\text { dos estudantes. }\end{array}$ \\
\hline Martins e & Webquest, & Laboratório de & Desenvolvimento do & Estudante surdo e os \\
\hline
\end{tabular}




\begin{tabular}{|c|c|c|c|c|}
\hline $\begin{array}{l}\text { Piemonte } \\
\text { (2018) }\end{array}$ & $\begin{array}{l}\text { Sway®e } \\
\text { Kahoot }{ }^{\circledR} .\end{array}$ & $\begin{array}{l}\text { informática, foi } \\
\text { necessário o uso } \\
\text { da internet. }\end{array}$ & $\begin{array}{l}\text { conteúdo de histologia } \\
\text { numa perspectiva } \\
\text { bilíngue para surdos } \\
\text { em classe de inclusão, } \\
\text { utilizando o Ensino } \\
\text { Híbrido com atividades } \\
\text { investigativas. }\end{array}$ & $\begin{array}{l}\text { ouvintes foram capazes de } \\
\text { construir seus } \\
\text { conhecimentos na disciplina } \\
\text { de Biologia de forma ativa. }\end{array}$ \\
\hline $\begin{array}{l}\text { Carvalho, } \\
\text { Castro, Maia, } \\
\text { Pinheiro } \\
(\mathbf{2 0 1 6 )}\end{array}$ & $\begin{array}{l}\text { Software } \\
\text { matemático, } \\
\text { "equilibrando } \\
\text { Proporções". }\end{array}$ & $\begin{array}{l}\text { Laboratório de } \\
\text { informática com } \\
\text { uso de internet, } \\
\text { videotecas. }\end{array}$ & $\begin{array}{l}\text { Planejado em conjunto } \\
\text { com todos os } \\
\text { participantes, dessa } \\
\text { maneira os } \\
\text { licenciandos passaram } \\
\text { a investigar e analisar o } \\
\text { OA "Equilibrando } \\
\text { Proporções". }\end{array}$ & $\begin{array}{l}\text { O objeto de aprendizagem } \\
\text { "Equilibrando Proporções" é } \\
\text { relevante para o } \\
\text { entendimento do conceito de } \\
\text { grandezas diretamente } \\
\text { proporcionais e de função } \\
\text { linear. }\end{array}$ \\
\hline $\begin{array}{l}\text { Araujo, } \\
\text { Bracho } \\
(\mathbf{2 0 1 9})\end{array}$ & $\begin{array}{l}\text { Dois } \\
\text { simuladores } \\
\text { elaborados } \\
\text { com o } \\
\text { software } \\
\text { GeoGebra. }\end{array}$ & $\begin{array}{l}\text { Funciona em } \\
\text { muitos sistemas } \\
\text { operacionais e } \\
\text { desde na } \\
\text { internet, por } \\
\text { tanto, os } \\
\text { simuladores } \\
\text { feitos com } \\
\text { GeoGebra. }\end{array}$ & $\begin{array}{l}\text { Após gerar debates e } \\
\text { reflexões em relação às } \\
\text { respostas dos } \\
\text { estudantes, o professor } \\
\text { pode começar o } \\
\text { trabalho com o } \\
\text { simulador, entrando no } \\
\text { momento } 2 \text { do } \\
\text { planejamento da aula. }\end{array}$ & $\begin{array}{l}\text { Os OA e os simuladores } \\
\text { como possibilidades de } \\
\text { criação, exploração e uso de } \\
\text { materiais educativos } \\
\text { enriquecedores se os } \\
\text { professores de } \\
\text { Matemáticas e Ciências do } \\
\text { século XXI encontram-se } \\
\text { aptos as tendências } \\
\text { educativas. }\end{array}$ \\
\hline
\end{tabular}

Fonte: Elaborado pelos autores (2021).

Essa pesquisa possibilitou identificar que os tipos de ODA utilizados nos últimos 5 anos são: vídeos, animações, documentários, Movie Maker, jogos digitais: Game das Frações e Labirinto das Frações. Software Stellarium, Google drive, Google Forms, Site Planetabio. Plataforma educacional adota a filosofia WEB 2.0 (Aprendizagem Colaborativa ${ }^{14}$ ), Plataforma multimídia com imagens, sons típicos de uma situação de jogo esportivo. Softwares: Chemical Balance, Balanceamento de Equações Químicas e Reagentes Produtos e Excesso, Michaelis on-line dicionário (2015), Lara Croft, Google, Google Maps, Google Docs, Easely, Sites como construção do livro digital, Softwares e plataformas digitais, site Comic Creator template, site Stripcreator, HagáQuê. Plataforma digital com suporte de livros e atividades: Webquest, Sway®e Kahoot ${ }^{\circledR}$. Software matemático, “equilibrando Proporções”, e o software GeoGebra.

Logo, evidenciou-se que os ODA mais utilizados foram vídeos, jogos digitais, plataformas de ensino, softwares, ferramentas do google e simuladores para o ensino. Além disso, as TDIC mais utilizadas foram: Smartphones, Tabletes e computadores (desktop e Notebooks), com e sem internet.

Outrossim, com relação à metodologia de ensino, a análise apontou que foram bastante diferenciadas, a depender da necessidade de abrangência da área de conhecimento e da didática do professor para atingir os objetivos determinados nas pesquisas. Cabe mencionar 
que Corrêa et al. (2020) se utilizaram de apresentação da técnica Stop Motion, oficina, animações e socialização dos vídeos, com intuito de desenvolver a criatividade e autonomia dos estudantes. Na oficina Stop Motion foram elencadas duas temáticas: o conteúdo de Química Geral, a ser estudado pelo tópico "Evolução de Modelos atômicos" e os passos da produção das micrometragens, mostra técnica de fotografia, roteirização e edição de áudio e vídeo com o software Microsoft Movie Maker.

Os estudantes foram organizados em grupos de 5 ou 6 integrantes e apresentaram os conteúdos: teoria atômica de Dalton, modelo atômico de Rutherford, modelo atômico de Bohr e o modelo de subníveis de energia. Em seguida, os grupos elaboraram os roteiros para a produção do material audiovisual e receberam embasamento teórico sobre a técnica Stop Motion e materiais de apoio. Por fim, os grupos exibiram os vídeos em sala de aula, por meio de um intercâmbio divertido e prazeroso, apresentaram o conteúdo de forma contextualizada e, posteriormente, partilharam entre os estudantes, por meio do aplicativo WhatsApp.

Os pesquisadores Macêdo e Voelzke (2020) abordaram as metodologias de ensino por meio de atividades práticas de pesquisa, nas quais se aplicam os 3MPs, desenvolvidas com o apoio do software Stellarium (STELLARIUM, 2020), que é um simulador do céu com os principais corpos celestes, um ODA que possibilita antecipar a movimentação dos astros celestes, desperta a curiosidade e possibilidade de pesquisa, além de ser favorável para revisar ou aprofundar estudos e conceitos sobre à Astronomia observacional. Ademais, os autores aplicaram as atividades em uma turma de estudantes de licenciaturas em Física, Matemática e Ciências Biológicas, obtiveram um bom resultado, o que evidencia que o uso das TDIC contribuiu com a melhoria do ensino de Astronomia.

Além disso, Danhão, Frenedozo, Schimiguel e Coelho (2019) buscaram, na realização da pesquisa, desenvolver uma sequência com a aplicação de três testes: no Google Drive Forms, com dez questões de múltipla escolha cada um, utilização de um objeto digital de aprendizagem, o site Planetabio, com abordagem dos conteúdos de Zoologia dos invertebrados e dos vertebrados. Para tal atividade, foram disponibilizados aos estudantes os links dos testes para acesso pelos celulares. Depois de uma semana, foram instruídos a procurarem estudar pelo site Planetabio por uma hora e responderem novamente o questionário, o $2^{\circ}$ teste, aplicado com intervalo de quinze dias, e depois realizaram o $3^{\circ}$ teste. Os professores só orientaram os procedimentos, não explicaram conteúdo ou questão, mesmo assim os estudantes mostraram melhor desempenho no $2^{\circ}$ teste. Isso pode indicar influência do uso do objeto digital de aprendizagem Planetabio. 
Ademais, Oliveira, Carvalho, Kapitango-a-Samba (2019) apresentaram as aulas realizadas com duas professoras de química, as quais elencaram os seguintes conteúdos: reações químicas, balanceamento de equações químicas e estequiometria e selecionaram os ODA, a saber: Chemical Balance (encontrado na Loja Virtual PlayStore), 'Balanceamento de Equações Químicas e Reagentes Produtos e Excesso' (encontrados no site da Universidade do Colorado), todos gratuitos. Com apoio desses três ODA e das professoras foram construídas atividades com a ajuda desses recursos digitais, reservadas quatro horas/aulas para trabalhar com cada um dos ODA. Cada docente explicou os conteúdos, inclusive por meio dos ODA, e depois entregaram as atividades aos estudantes para serem realizadas em duplas. Por fim, concluíram a proposta pedagógica com a aplicação de entrevista estruturada aos estudantes, os quais deveriam se sentirem à vontade para dizerem sobre as limitações (aspectos negativos) e possibilidades (positivos) tanto da utilização dos ODA quanto dos próprios ODA.

No decorrer das análises, observou-se, também, que Martins e Piemonte (2018) valeram-se de atividades investigativas por meio do ensino híbrido e desenvolveram conteúdo de histologia numa perspectiva bilíngue para surdos em classe de inclusão. Verificou-se o uso de dois ODA, o primeiro, Sway® (uma construção colaborativa), com o qual o estudante surdo atribuiu na seção do seu grupo um vídeo em Libras produzido por ele e algumas informações em Língua Portuguesa escrita. O segundo ODA, o Kahoot® (jogo de histologia), poucos estudantes conheciam o jogo, houve grande interesse e vontade de acertar as questões apresentadas. Ao serem projetadas cada questão, todos ficavam em silêncio para lerem e rapidamente apertarem o botão correspondente à resposta, por meio desse aplicativo. A cada questão exposta, uma música acompanhava a contagem regressiva para clicar na resposta e provocava a atenção dos estudantes para tentar acertar rapidamente. Cabe evidenciar que o Kahoot ${ }^{\circledR}$ colaborou para a gamificação na sala de aula, por se apresentar como um jogo, o qual estabelece regras, retorno rápido, pontuação por acerto, disputa construtiva entre estudantes/equipes e, assim, observou-se muita diversão durante o processo educativo.

Verificou-se, ainda, que nas pesquisas realizadas foram alcançados os objetivos previstos relacionados aos componentes curriculares de Ciências Naturais. Nessa perspectiva, Corrêa et al. (2020) obtiveram os resultados da construção de 6 (seis) micrometragens de animação, enquanto Macêdo e Voelzke (2020) relataram atingir os objetivos, os quais contribuíram para formação inicial de professores, por meio de uma atividade proposta no ensino de astronomia.

Danhão, Frenedozo, Schimiguel e Coelho (2019) enfatizaram uma melhora no desempenho dos estudantes ao utilizarem os ODA durante o processo de aprendizagem. Nesse 
pensar, Oliveira, Carvalho, Kapitango-a-Samba (2019) destacaram que sua pesquisa permitiu demonstrar que os ODA possuem possibilidades de motivar e mobilizar conhecimento, dinamizar o ensino e auxiliar a aprendizagem. Por fim, Martins e Piemonte (2018) relataram obter resultados importantes no ensino de estudantes surdos e ouvintes, que foram capazes de construírem seus conhecimentos na disciplina de Biologia de forma ativa.

Portanto, os ODA identificados nesta pesquisa possibilitam a motivação, a mobilização dos conhecimentos científicos, dinamizaram o ensino e deram significado à aprendizagem. A exemplificação dos conteúdos, que utilizou a linguagem visual, permitiu visualização de uma gama de conceitos de várias áreas do saber, o que contribuiu para melhorar a compreensão desses. Por outro lado, também foram observadas limitações quanto a alguns ODA, tais como: não permitirem feedback, apresentarem conceitos curriculares incompletos do Ensino Médio ou Fundamental, terem interface limitada e não oferecem suporte, ou seja, a ajuda necessária para resolução de algumas atividades, o que pode influenciar negativamente no processo educativo. Contudo, cabe ressaltar que são mais contribuições do que limitações, ou seja, acredita-se que os ODA favoreçam a construção do conhecimento e, por isso, defende-se sua utilização no Ensino de Ciências.

\section{CONSIDERAÇÕES FINAIS}

Devido à pandemia provocada pelo novo Coronavírus, milhões de estudantes do Ensino Fundamental precisaram se ausentar dos espaços escolares e, com isso, há déficits de aprendizagem em todas as áreas dos componentes curriculares da BNCC. Nessa perspectiva, para tentar diminuir as distâncias, melhorar e minimizar perdas no processo educativo, principalmente no que diz respeito ao Ensino de Ciências, pode-se utilizar os ODA demonstrados nas análises, os quais os autores evidenciaram uma melhora do aprendizado em todas as aplicações práticas em sala de aula.

Neste estudo foi possível realizar o levantamento da produção científica dos últimos cinco anos sobre ODA, uma tendência educacional global como instrumento eficaz, flexível e dinâmico, que pode influenciar direta ou indiretamente nas aulas, deixá-las mais interativas, facilitar a mediação do educador e proporcionar aulas agradáveis e atrativas para os estudantes.

Ademais, quanto aos procedimentos desta pesquisa, é notória a importância das produções científicas no que se referem a conhecerem diferentes trabalhos já realizados e a descoberta de lacunas que estimulam o desenvolvimento de outros estudos, a partir desses 
saberes. Para o levantamento sistemático específico, é de grande valor um debate crítico sobre as atuais pesquisas científicas.

Outrossim, sobre a temática/assunto abordado, ressalta-se o uso de ODA no Ensino de Matemática. No Ensino de Ciências sua utilização está voltada a experiências e atividades práticas, porém todas direcionadas ao Ensino Médio. Quanto ao tipo de pesquisa mais adotado nesses estudos, destaca-se a investigação em campo e a análise documental, sendo a abordagem qualitativa predominante.

Além do mais, referente ao público envolvido/campo de investigação, professores e estudantes foram os mais investigados. São apontadas como referências basilares de ODA: Almeida (2014); Barros (2008); Lévy (1999); Rojo (2012); Santaella (2003); Tarouco (2006); Valente (2011) e Wiley (2000). Para além, os ODA mais utilizados foram: vídeos, jogos digitais, plataformas de ensino, softwares, ferramentas do google e simuladores para o ensino. Quanto às TDIC mais manuseadas foram: Smartphones, Tabletes e computadores (desktop e Notebooks) com e sem internet. Dessa forma, as metodologias de ensino empregadas na utilização dos ODA foram diversificadas, de acordo com cada contexto.

Com a realização desta pesquisa, nota-se que utilizar ODA no Ensino de Ciências melhorou a compreensão de determinados conteúdos pelos estudantes, o que demonstra a eficiência desses objetos para a aprendizagem. Apesar das dificuldades de se encontrar ODA gratuitos e compatíveis com os componentes curriculares dessa área do conhecimento, os professores não mediram esforços e conseguiram empregar vários em suas aulas.

Além disso, dentre as principais lacunas, observou-se, a partir das análises, que nenhuma produção científica foi realizada no Ensino Fundamental, concernente ao Ensino de Ciências Naturais. Acredita-se que os ODA no Ensino de Ciências deveriam ser pesquisados e utilizados desde os anos iniciais do Ensino Fundamental, pois notou-se que eles causam impactos na aprendizagem dos estudantes.

Cabe ressaltar que uma sugestão para investigações futuras é ampliação das plataformas de buscas bibliográficas, tais como Web of Science, Pubmed, Google Scholar, dentre outras. Além disso, a proposta de investigação do Mestrado é de coletar informações à campo com professores de Ciências Naturais do Ensino Fundamental, os quais provavelmente utilizam ODA em suas práticas pedagógicas, o que permitirá compreender as contribuições, potencialidades, limitações e dificuldades ao utilizarem estas ferramentas pedagógicas em sala de aula.

Logo, conclui-se este texto com a convicção de que é preciso ampliar as investigações sobre o assunto, apropriar-se de tais conhecimentos e perspectivas relacionadas com o 
problema que se anseia entender e solucionar, o que pode, de fato, contribuir para melhorias na prática docente, no processo educativo e, consequentemente, no Ensino de Ciências.

\section{REFERÊNCIAS}

AGUIAR, Eliane Vigneron Barreto; FLÔRES, Maria Lucia Pozzatti. Objetos de aprendizagem: conceitos básicos. In: TAROUCO, Lidiane Maria Rockenbach et. al. (orgs.) Objetos de Aprendizagem: teoria e prática. Porto Alegre: Evangraf, 2014.

ALEXANDRE, Mariana dos Reis. Objetos Digitais de Aprendizagem e os estilos de uso do virtual: estreitando relações e construindo diálogos. Indagatio Didactica, vol. 12 (5), dez., 2020. Disponível em: https://proa.ua.pt/index.php/id/article/view/23463. Acesso em: 16 mai. 2021.

ALVES, Ivelise Kraide; VELHO, André Ricardo Theodoro; BARWALDT, Regina. Repensando a forma de ensinar e aprender a divisão por meio das Tecnologias Digitais.

REMAT: Revista Eletrônica da Matemática, v. 2, n. 2, p. 105-121, nov., 2016. Disponível em: https://www.periodicos.ifrs.edu.br/index.php/REMAT/article/view/1552. Acesso em: 16 mai. 2021.

ARAUJO, Rafael Enrique Gutiérrez; BRACHO, Luis Andrés Castillo. Simuladores com o software GeoGebra como objetos de aprendizagem para o ensino da física. TED, n. 47, Primer semestre de 2020. ISSN 2665-3184 pp. 201-216. Disponível em:

https://www.researchgate.net/publication/340231256_Simuladores_com_o_software_GeoGeb ra_como_objetos_de_aprendizagem_para_o_ensino_da_fisica. Acesso em: 16 mai. 2021.

BARDIN, Laurence. Análise de Conteúdo. São Paulo: Edições 70, 2016.

BRASIL. Parâmetros Curriculares Nacionais: Ciências da Natureza e Matemática e suas tecnologias. BRASÍLIA: MEC, 2000.

BRASIL. RIVED: Rede Interativa Virtual de Educação. Ministério da Educação. Secretaria de Educação a Distância. Brasília: MEC/SEED, 2007. Disponível em:

http://rived.mec.gov.br/. Acesso em: 17 mai. 2021.

BRASILEIRO, Lilian Borges; SILVA, Glenda Rodrigues da. Interatividade na Ponta do Mouse: simulações e laboratórios virtuais. In: MATEUS, Alfredo Luis (org). Ensino de Química Mediado pelas TICs. Belo Horizonte: UFMG, 2015.

BRIGGS, Asa; BURKE, Peter. Uma história social da mídia: de Gutenberg à Internet. Trad. Maria Carmelita Pádua Dias. Rio de Janeiro: Jorge Zahar Ed., 2004.

CAMILLO, Cíntia Moralles; MEDEIROS, Liziany Muller. A Importância dos Jogos Digitais no Contexto Escolar. Competência. Porto Alegre, v.11, n. 1, jul., 2018. Disponível em: http://seer.senacrs.com.br/index.php/RC/article/view/555/317. Acesso em: 16 mai. 2021.

CARDOSO, Maria Clara Santos do Amaral; SAMPAIO, Aleandra da Silva Figueira.

Dificuldades para o uso da informática no ensino: percepção dos professores de matemática após 40 anos da inserção digital no contexto educacional brasileiro. Educação Matemática 
Pesquisa. São Paulo, vol. 21, ed. 2, 2019. DOI:10.23925/1983-3156.2018v21i2p044-084. Disponível em: https://www.proquest.com/docview/2285077512? accountid=201395. Acesso em: 15 mai. 2021.

CARNEIRO, Mara Lúcia Fernandes; SILVEIRA, Milene Selbach. Objetos de aprendizagem sob o ponto de vista dos alunos: um estudo de caso. RENOTE. Revista Novas Tecnologias na Educação, v. 10, n.3, p. 363-393, dez., 2012. Disponível em:

http://www.cinted.ufrgs.br/ciclo20/artigos/4d-mara.pdf. Acesso em: 15 mai. 2021.

CARVALHO, Rodrigo Lacerda et al. Contribuições do Campo Conceitual Multiplicativo para a Formação Inicial de Professores com Suporte das Tecnologias Digitais. Educação

Matemática Pesquisa. São Paulo, vol. 18, ed. 1, 2016. Disponível em:

https://www.proquest.com/docview/1787100603?accountid=201395. Acesso em: 16 mai. 2021.

CHINAGLIA, Juliana Vegas; MENDONÇA, Márcia. Materiais Didáticos para os Novos e Multiletramentos: uma proposta de atividade Gamificada. Revista Linguagem em Foco, [S. 1.], v. 9, n. 1, p. 39-52, 2017. Disponível em:

https://revistas.uece.br/index.php/linguagememfoco/article/view/1533. Acesso em: 16 mai. 2021.

CORREAA, Taís Arthur et al. Uma experiência didática através da ferramenta Stop Motion para o ensino de modelos atômicos. HOLOS, [S.1.], v. 6, p. 1-12, dez., 2020. ISSN 18071600. Disponível em: http://www2.ifrn.edu.br/ojs/index.php/HOLOS/article/view/9986. Acesso em: 15 mai. 2021.

DANHÃO, Elizabeth Aparecida Assis Brandão et al. Influência de Objetos Digitais de Aprendizagem nas concepções de conceitos de Zoologia, uma experiência em Portugal.

Revista de Ensino de Ciências e Matemática, v. 10, n. 4, p. 89-100, 18 jul., 2019.

Disponível em:

https://revistapos.cruzeirodosul.edu.br/index.php/rencima/article/view/2434/1148. Acesso em: 15 mai. 2021.

DEIDMAR, G.L.C; SOBREIRA, D.S; LIMA, W.D. Internet das coisas na Educação. Revista Tecnologias em Projeção, v. 8. n. 2, ano 2017. p. 68

FARINELLI, Fernanda. Conceitos Básicos de Programação Orientada a Objetos, 2007. Disponível em: www.jack.eti.br/www/arquivos/apostilas/java/poo.pdf. Acesso em: 17 mai. 2021.

FELCHER, Carla Denize Ott; PINTO, Ana Cristina Medina; FOLMER, Vanderlei. Tendências em Tecnologias digitais no Ensino da Matemática Reveladas no EBRAPEM. Educação Matemática Pesquisa. São Paulo, vol. 21, ed. 2, 2019. DOI: 10.23925/19833156.2018v21i2p001-022. Disponível em: https://www.proquest.com/docview/2285076658?accountid=201395. Acesso em: 15 mai. 2021.

FUJITA, Oscar Massaru; RODRIGUES, Erika Navarro. A contextualização e os objetos digitais de aprendizagem na educação básica: o currículo e a sua aplicação na matemática. 
Educação Matemática Pesquisa. São Paulo, vol. 18, ed. 2, 2016. Disponível em:

https://www.proquest.com/docview/1836756014?accountid=201395. Acesso em: 15 mai. 2021.

GIL, Antônio Carlos. Como elaborar projetos de pesquisa. 6. ed. São Paulo: Atlas, 2017.

GOMES, Rosilvaldo. Análise Linguística e Objetos Digitais de Aprendizagem. Revista Linguagem em Foco, [S. 1.], v. 9, n. 1, p. 53-64, 2017. Disponível em:

https://revistas.uece.br/index.php/linguagememfoco/article/view/1534. Acesso em: 16 mai. 2021.

GOUVEIA, Luís Borges; SILVA, Armando Malheiro. A infocomunicação ou a convergência das ciências da informação e da comunicação para um objeto comum. Páginas A \& B; Oporto. Edição especial, 2020. p.15-33. Disponível em: https://ojs.letras.up.pt/index.php/paginasaeb/article/view/7814/7171. Acesso em: 15 mai. 2021.

HODGINS, H. Wayne. The Future of Learning Objects in e-Technologies in Engineering Education: Learning Outcomes Providing Future Possibilities, Jack R. Lohmann, Georgia Institute of Technology, USA; Michael L. Corradini, University of Wisconsin-Madison, USA Eds, ECI Symposium Series, 2002. Disponível em: https://dc.engconfintl.org/etechnologies/11. Acesso em: 16 mai. 2021.

KAMINSKI, Márcia Regina et al. Uso de jogos digitais em práticas pedagógicas realizadas em distintos contextos escolares. Educação Matemática Pesquisa. São Paulo, vol. 21, ed. 2, 2019. DOI:10.23925/1983-3156.2018v21i2p288-312. Disponível em: https://www.proquest.com/docview/2285076627?accountid=201395. Acesso em: 15 mai. 2021.

KÖCHE, José Carlos. Fundamentos de metodologia científica: teoria da ciência e iniciação à pesquisa. 30. ed. Petrópolis: Vozes, 2012.

LÜDKE, Menga; ANDRÉ, Marli. E. D. A. Pesquisa em educação: abordagens qualitativas. 2. ed. São Paulo: EPU, 2013.

MACÊDO, Josué Antunes de; VOELZKE, Marcos Rincon. Aprendizagem significativa, Objetos de aprendizagem e o ensino de Astronomia. Revista de Ensino de Ciências e Matemática, v. 11, n. 5, p. 1-19, ago., 2020. Disponível em: https://revistapos.cruzeirodosul.edu.br/index.php/rencima/article/view/2726/1319. Acesso em: 15 mai. 2021.

MARTINS, Joseane Maria Rachid. Objetos Digitais de Aprendizagem como Ferramenta Metodológica para o Ensino de Ciências sob uma Perspectiva Inclusiva. Universidade Tecnológica Federal do Paraná - UTFPR. Ficha de Identificação - Produção Didáticopedagógica Professor PDE, 2013. Disponível em:

http://www.diaadiaeducacao.pr.gov.br/portals/cadernospde/pdebusca/producoes_pde/2013/20 13_utfpr_cien_pdp_joseane_maria_rachid_martins.pdf . Acesso em: 16 mai. 2021.

MARTINS, Joseane Maria Rachid; PIEMONTE, Mariana da Rocha. Ensino Híbrido de Histologia em Turmas de Inclusão de Surdos. Revista Prática Docente, [S. 1.], v. 5, n. 3, p. 
1865-1883, 2020. DOI: 10.23926/RPD.2526-2149.2020.v5.n3.p1865-1883.id863. Disponível em: http://periodicos.cfs.ifmt.edu.br/periodicos/index.php/rpd/article/view/863. Acesso em: 16 mai. 2021.

MARTINS, Silvana Neumann et al. Objetos Digitais para a Aprendizagem da Leitura: uma metodologia ativa de ensino. Calidoscópio, vol. 14, n. 3, p. 413-422, 2016. Disponível em: http://revistas.unisinos.br/index.php/calidoscopio/article/view/cld.2016.143.05. Acesso em: 16 mai. 2021.

MATTAR, Fauze Najib. Pesquisa de marketing. 3. ed. São Paulo: Atlas, 2001.

MORAN, José Manuel et al. Novas tecnologias e mediação pedagógica. 6. ed. Campinas: Papirus, 2000.

MORAN, José Manuel. Novas tecnologias e o re-encantamento do mundo. Tecnologia Educacional. Rio de Janeiro, vol. 23, n. 126, setembro-outubro, 1995, pág. 24-26.

MOROSINI, Marília Costa; FERNANDES, Cleoni Maria Barboza. Estado do Conhecimento: conceitos, finalidades e interlocuções. Educação Por Escrito. Porto Alegre, v. 5, n. 2, p. 154164, jul.-dez., 2014.

MINAYO, Maria Cecília de Souza. O desafio do conhecimento. 11 ed. São Paulo: Hucitec, 2008.

OLIVEIRA, Fabio Caires de; et al.. QUILEGAL: Um recurso para o ensino de Ciências Naturais. South American Journal of Basic Education, Technical and Technological , [S. 1.], v. 8, n. 2, p. 707-730, 2021. Disponível em: https://revistas.ufac.br/index.php/SAJEBTT/article/view/4216. Acesso em: 1 nov. 2021.

OLIVEIRA, Maria Edivania Rodrigues da Silva Neves de. et al. Objetos Digitais de Aprendizagem como Recurso Mediador do Ensino de Química. Revista Cocar, v.13, n. 27, set./dez., 2019. p.1005-1021 ISSN: 2237-0315. Disponível em:

https://periodicos.uepa.br/index.php/cocar/article/view/2882. Acesso em: 16 mai 2021.

OLIVEIRA, Sergio Batista, COELHO Neto, João. Objetos de aprendizagem e o ensino da matemática: contextos e aplicações acerca de sua utilização em mestrados profissionais na área de ensino. Revista Conhecimento Online. v. 3, set.-dez., 2019. Disponível em: https://periodicos.feevale.br/seer/index.php/revistaconhecimentoonline/article/view/1865. Acesso em: 16 mai. 2021.

PERFETTO, Fabio Viana; ALBUQUERQUE, Ana Cristina de. O tratamento dos Objetos Virtuais de Aprendizagem como recursos informacionais na criação, uso e recuperação da informação. Brazilian Journal of Information Science: Research Trends. Marília, vol. 12, ed. 3, 2018. DOI:10.5016/brajis.v12i3.8168. Disponível em: https://www.proquest.com/docview/2116456572?accountid=201395. Acesso em: 15 mai. 2021.

RODRIGUES, V. A origem da internet. Ministério da Educação, 2008. Disponível em: https://www.grupoescolar.com/pesquisa/a-origem-da-internet.html. Acesso em: 17 mai. 2021. 
SILVA, Ananias Agostinho da. Gêneros digitais e alfabetização: propostas com as histórias em quadrinho. Domínios de Lingu@gem, v. 14, n. 3, p. 763-789, abr., 2020. ISSN 19833652DOI: 10.17851/1983-3652.11.3.102-130. Disponível em: http://www.seer.ufu.br/index.php/dominiosdelinguagem/article/view/47588. Acesso em: 16 mai. 2021.

SILVA, Luciana Pereira; RUTIQUEWISKI, Andreia; BENATTI, Juliana. Os Objetos Educacionais Digitais em Linguagem e Interação: avanços, permanências ou retrocessos. Revista Texto Livre. Belo Horizonte, v. 11, n. 3, p. 102-130, set.-dez., 2018. ISSN 19833652DOI: 10.17851/1983-3652.11.3.102-130.

http://periodicos.letras.ufmg.br/index.php/textolivre. Acesso em: 16 mai. 2021.

SILVA, Simone dos Santos Venturelli Antunes; FERRAZ, Denise Pereira de Alcantara. A visão do professor sobre jogos digitais no Ensino da Matemática para alunos com deficiência intelectual: Estado da arte. Educação Matemática Pesquisa. São Paulo, vol. 21, ed. 1, 2019. DOI: 10.23925/1983-3156.2019v21i1p180-196. Disponível em: https://www.proquest.com/docview/2220208509?accountid=201395. Acesso em: 15 mai. 2021.

TALLEI, Jorgelina Ivana Tallei; SILVA, Elaine Teixeira da. Receita para criar objetos digitais nas aulas de espanhol como língua estrangeira. In: FETTERMANN, Joyce Vieira; CAETANO, Joane Marieli Pereira. (orgs). Ensino de línguas e novas tecnologias: diálogos interdisciplinares. Campos dos Goytacazes, RJ: Brasil Multicultural, 2016. p. 118-129.

TAROUCO, Liane Margarida Rokenbach. Objetos de aprendizagem e a EAD. In: LITTO, Fredric Michael; FORMIGA, Manuel Marcos Maciel. (Orgs.). Educação a distância: o estado da arte. 2. ed. São Paulo: Person Education do Brasil, 2012. p. 83-92.

TRIVIÑOS, Augusto Nibaldo Silva. Introdução à pesquisa em ciências sociais: a pesquisa qualitativa em educação. São Paulo: Atlas, 1987.

WILEY, David. A. Connecting learning objects to instructional design theory: A definition, ametaphor, and a taxonomy. 2000. In: WILEY, David A. (ed.), The Instructional Use of Learning Objects: Online Version. Disponível em: http://reusability.org/read/chapters/wiley.doc. Acesso em: 17 mai. 2021.

\section{APÊNDICE 1}

\section{AGRADECIMENTOS}

Ao Programa de Pós-Graduação Stricto Sensu em Ensino, ofertado pela Associação Ampla entre IFMT/UNIC, pela formação recebida.

\section{FINANCIAMENTO}

Não se aplica.

\section{CONTRIBUIÇÕES DE AUTORIA}

Resumo/Abstract/Resumen: Marcelo Franco Leão

Introdução: Jefferson Batistella e Marcelo Franco Leão

Referencial teórico: Jefferson Batistella e Marcelo Franco Leão

Análise de dados: Jefferson Batistella e Marcelo Franco Leão 
Discussão dos resultados: Jefferson Batistella e Marcelo Franco Leão Conclusão e considerações finais: Jefferson Batistella e Marcelo Franco Leão Referências: Jefferson Batistella

Revisão do manuscrito: Gislane Aparecida Moreira Maia, Jefferson Batistella e Marcelo Franco Leão Aprovação da versão final publicada: Jefferson Batistella e Marcelo Franco Leão

Obs.: Além destas etapas supracitadas, a Revista REAMEC recomenda a utilização, caso seja necessário, da Taxonomia de Funções de Contribuidor (CRediT). CRediT é uma taxonomia de alto nível, incluindo 14 funções que podem ser usadas para representar as funções normalmente desempenhadas por contribuidores para a produção científica acadêmica. As funções descrevem a contribuição específica de cada contribuidor para a produção acadêmica. São elas: (1) Conceituação; (2) Curadoria de dados; (3) Análise formal; (4) Aquisição de financiamento; (5) Investigação; (6) Metodologia; (7) Administração do projeto; (8) Recursos; (9) Software; (10) Supervisão; (11) Validação; (12) Visualização; (13) Redação - esboço original; (14) Redação - revisão e edição. Para mais informações sobre estas funções, conferir em: https://casrai.org/credit/.

Os papéis dados na taxonomia acima incluem, mas não estão limitados a papéis tradicionais de autoria. Os papéis não têm como objetivo definir o que constitui autoria, mas, em vez disso, capturar todo o trabalho que permite a produção de publicações acadêmicas.

\section{CONFLITOS DE INTERESSE}

Os autores declararam não haver nenhum conflito de interesse de ordem pessoal, comercial, acadêmico, político e financeiro referente a este manuscrito.

\section{DISPONIBILIDADE DE DADOS DE PESQUISA}

O conjunto de dados que dá suporte aos resultados da pesquisa foi publicado no próprio artigo.

\section{CONSENTIMENTO DE USO DE IMAGEM}

Não se aplica.

\section{APROVAÇÃO DE COMITÊ DE ÉTICA EM PESQUISA \\ Não se aplica.}

\section{COMO CITAR - ABNT}

BATISTELLA, Jefferson; LEÃO, Marcelo Franco. PRODUÇÃO CIENTÍFICA SOBRE OBJETOS DIGITAIS DE APRENDIZAGEM VOLTADOS PARA O ENSINO DE CIÊNCIAS (2016-2020). REAMEC - Rede Amazônica de Educação em Ciências e Matemática. Cuiabá, v. 9, n., 3, e21098, set./dez., 2021. http://dx.doi.org/10.26571/reamec.v9i3.12902.

\section{COMO CITAR - APA}

Batistella, J. \& Leão, M. F. (2021). PRODUÇÃO CIENTÍFICA SOBRE OBJETOS DIGITAIS DE APRENDIZAGEM VOLTADOS PARA O ENSINO DE CIÊNCIAS (2016-2020). REAMEC - Rede Amazônica de Educação em Ciências e Matemática, 9 (3), e21098. http://dx.doi.org/10.26571/reamec.v9i3.12902.

\section{LICENÇA DE USO}

Licenciado sob a Licença Creative Commons Attribution-NonCommercial 4.0 International (CC BY-NC 4.0). Esta licença permite compartilhar, copiar, redistribuir o manuscrito em qualquer meio ou formato. Além disso, permite adaptar, remixar, transformar e construir sobre o material, desde que seja atribuído o devido crédito de autoria e publicação inicial neste periódico.

\section{DIREITOS AUTORAIS}

Os direitos autorais são mantidos pelos autores, os quais concedem à Revista REAMEC - Rede Amazônica de Educação em Ciências e Matemática - os direitos exclusivos de primeira publicação. Os autores não serão remunerados pela publicação de trabalhos neste periódico. Os autores têm autorização para assumir contratos adicionais separadamente, para distribuição não exclusiva da versão do trabalho publicada neste periódico (ex.: publicar em repositório institucional, em site pessoal, publicar uma tradução, ou como capítulo de livro), com reconhecimento de autoria e publicação inicial neste periódico. Os editores da Revista têm o direito de proceder a ajustes textuais e de adequação às normas da publicação.

\section{PUBLISHER}

Universidade Federal de Mato Grosso. Programa de Pós-graduação em Educação em Ciências e Matemática (PPGECEM) da Rede Amazônica de Educação em Ciências e Matemática (REAMEC). Publicação no Portal de 
Periódicos UFMT. As ideias expressadas neste artigo são de responsabilidade de seus autores, não representando, necessariamente, a opinião dos editores ou da referida universidade.

\section{EDITOR}

Patrícia Rosinke (iD) $(2$

\section{HISTÓRICO}

Submetido: 26 de agosto de 2021.

Aprovado: 13 de outubro de 2021.

Publicado: 27 de novembro de 2021. 